OPEN ACCESS

Edited by: Pobitra Halder, RMIT University, Australia

Reviewed by:

Riyang Shu,

Guangdong University of Technology,

China

Xiaoming Huang,

Dalian University of Technology, China

*Correspondence: H. P. Vasantha Rupasinghe vrupasinghe@dal.ca

Specialty section: This article was submitted to

Bioenergy and Biofuels,

a section of the journal

Frontiers in Energy Research

Received: 14 August 2021 Accepted: 20 December 2021

Published: 11 January 2022

Citation:

Zhou N, Thilakarathna WPDW, He QS and Rupasinghe HPV (2022) A Review: Depolymerization of Lignin to Generate High-Value Bio-Products: Opportunities, Challenges, and Prospects

Front. Energy Res. 9:758744. doi: 10.3389/fenrg.2021.758744

\section{A Review: Depolymerization of Lignin to Generate High-Value Bio-Products: Opportunities, Challenges, and Prospects}

\author{
Ningning Zhou ${ }^{1}$, W. P. D. Wass Thilakarathna ${ }^{2}$, Quan Sophia $\mathrm{He}^{1}$ and \\ H. P. Vasantha Rupasinghe ${ }^{2 *}$
}

${ }^{1}$ Department of Engineering, Faculty of Agriculture, Dalhousie University, Truro, NS, Canada, ${ }^{2}$ Department of Plant, Food, and Environmental Sciences, Faculty of Agriculture, Dalhousie University, Truro, NS, Canada

Lignin is identified as a promising candidate in renewable energy and bioproduct manufacturing due to its high abundance, polymeric structure, and biochemical properties of monomers. Thus, emerging opportunities exist in generating high-value small molecules from lignin through depolymerization. This review aims at providing an overview of the major technologies of lignin depolymerization. The feasibility of large-scale implementation of these technologies, including thermal, biological, and chemical depolymerizations, are discussed in relation to potential industrial applications. Lignin as a renewable alternative to petroleum-based chemicals has been well documented. This review attempts to emphasize potential applications of lignin-derived monomers and their derivatives as bioactives in food, natural health product, and pharmaceutical sectors. The critical review of the prospects and challenges of lignin-derived bioproducts reveals that the advancement of research and development is required to explore the applications of depolymerization of lignins to their full potential.

Keywords: lignin, depolymerization, lignin-first biorefining, vanillin, syringaldehyde, ferulic acid

\section{INTRODUCTION}

In the contexts of population expansion, climate change, resource depletion, and industrial development, biomass has received great interest as an attractive renewable resource for biofuel, biomaterial, and value-added chemicals production. Cellulose, hemicellulose, and lignin are the main polymeric fractions of lignocellulosic biomass with diverse chemical structures and physical properties. Among the three polymeric components, lignin is relatively underutilized and traditionally used for low-tech heat and power generation as a byproduct of paper and pulp processing with high heating value, which calls for further investigation to reach its full potential (Xu et al., 2014; Vinardell and Mitjans, 2017).

Second, only to cellulose, lignin is the most abundant natural biopolymer on earth, accounting for $20-35 \%$ of the dry biomass weight, and it is the largest natural source of renewable aromatic chemicals (Feofilova and Mysyakina, 2016; Li and Takkellapati, 2018). Lignin contributes to the strength of the plant cell wall by filling the space between cellulose and hemicellulose, as well as binding the lignocellulose matrix together (Zhou et al., 2021). Lignin has a highly-branched and amorphous chemical structure that varies considerably with biomass species and isolation techniques (Borcsok and Pasztory, 2021). It is a 3-dimensional heterogeneous biopolymer 


\section{A p-Coumaryl alcohol B Coniferyl alcohol C Sinapyl alcohol}

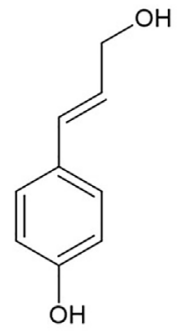<smiles>COc1cc(/C=C/CO)ccc1O</smiles><smiles>COc1cc(/C=C/CO)cc(OC)c1O</smiles>

FIGURE 1 | Three monolignols of lignin heterogeneous structure. (A) p-Coumaryl alcohol, (B) Coniferyl alcohol, (C) Sinapyl alcohol.

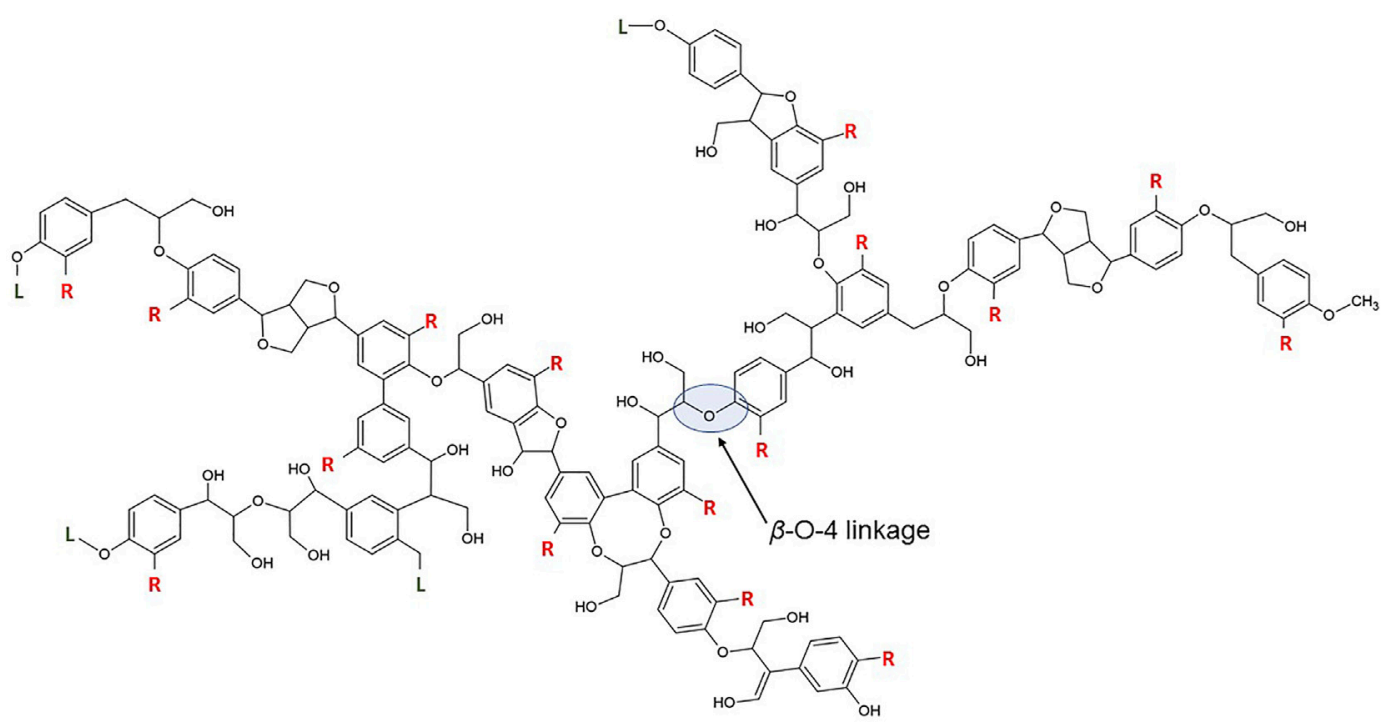

FIGURE 2 | Chemical structure of lignin polymer. L, lignin molecules; R, $\mathrm{H}$ or $-\mathrm{OCH}_{3}$.

formed by radical polymerization of three monolignols (Figure 1), including $p$-coumaryl, coniferyl, and sinapyl alcohols (Chen and Wan, 2017).

The radical coupling of these monolignols (Figure 2) results in the formation of different inner-unit linkages, mainly ether bonds (e.g., $\beta$-O-4, $\alpha-\mathrm{O}-4$, and 4-O-5) and C-C bonds (e.g., $\beta$ $1, \beta-5,5-5$ ' and $\beta-\beta$ ) (Wang et al., 2016). Most of the inner-unit linkages are $\beta$-aryl ether bonds, which makes up approximately $35-60 \%$ and $50-80 \%$ of linkages in softwood and hardwood, respectively (Feghali et al., 2020). The reactivity of lignin molecules is determined by the availability of functional groups, mainly methoxyl, aliphatic hydroxyl, phenolic, benzyl alcohol, non-cyclic benzyl ether, and carbonyl chemical groups (Katahira et al., 2018).

Availability of functional chemical groups, high antioxidant capacity, and biodegradability of lignin qualify it as a promising raw material for the synthesis of value-added bioproducts through the biorefining process. Lignin is recently identified as a valuable candidate for the production of hydrocarbons (e.g., benzyl, toluene, and xylene [BTX] chemicals), simple phenols (e.g., catechol, eugenol, vanillin, and quinones), polymeric macromolecules (e.g., carbon fiber and thermosets), nutraceuticals, drugs, and cosmetics (Xu and Ferdosian, 2017). However, the high chemical stability and natural complexity of lignin significantly restrict its applications, urging for environmentally sound, cost-effective, efficient, and simple technologies to degrade lignin into useful bioproducts. The objective of this article is to review the most recently reported major technologies of lignin depolymerization and to discuss their potential industrial applications. The review also provides prospects and challenges of lignin-derived 


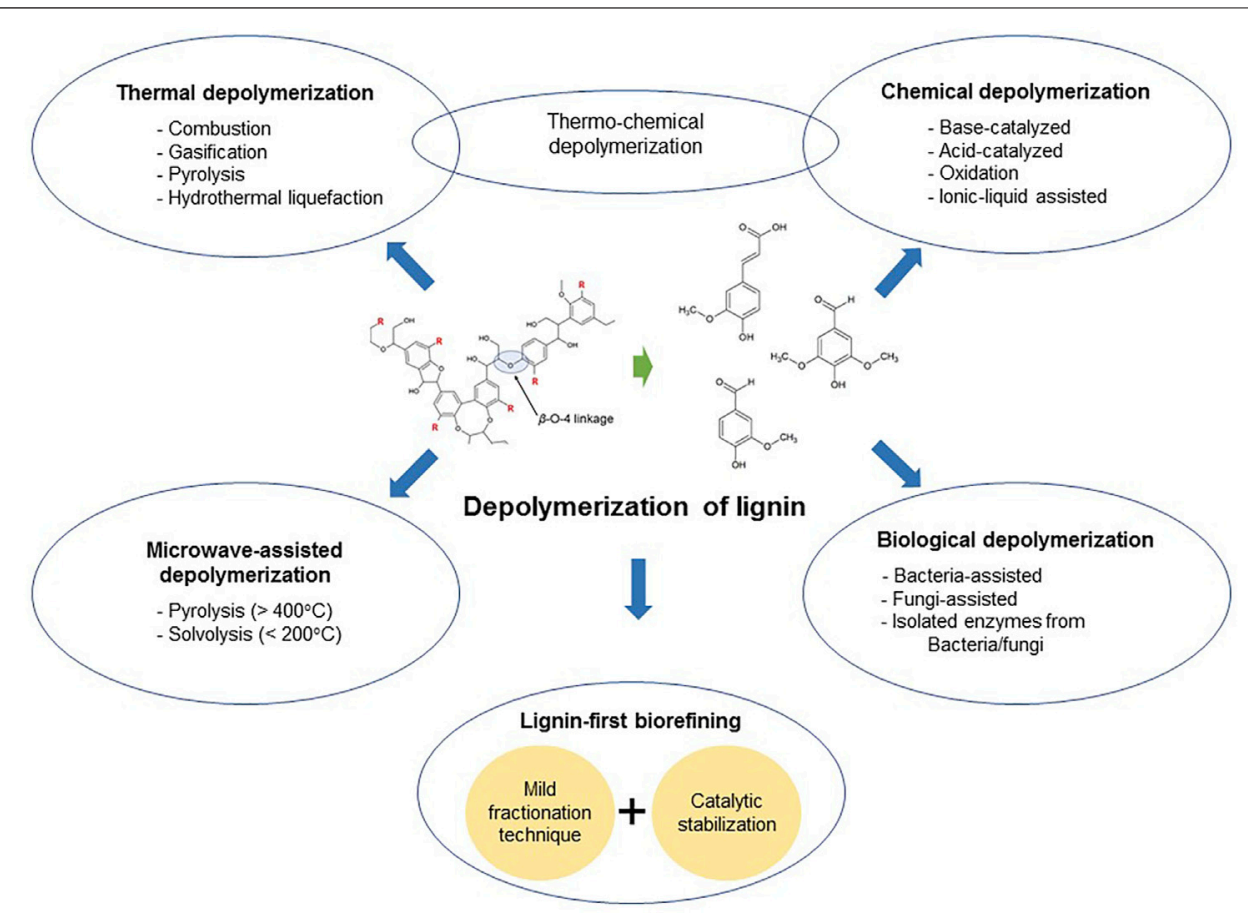

FIGURE 3 | Different technologies of lignin depolymerization.

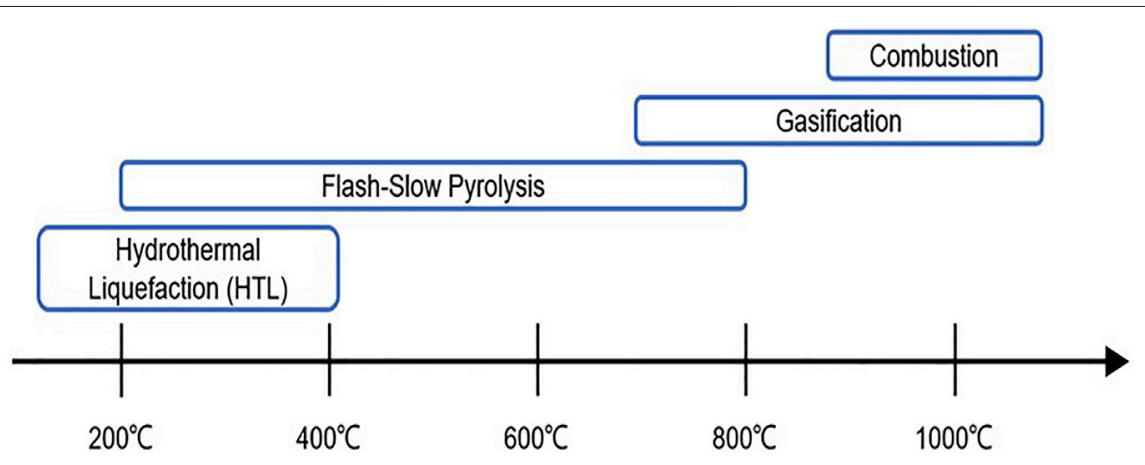

FIGURE 4 | Ranges of reaction temperatures used by different lignin thermal depolymerization methods.

bioproducts and reveals that the advancement of research and development is required to explore the applications of depolymerization of lignins to their full potential.

\section{AN OVERVIEW OF LIGNIN DEPOLYMERIZATION TECHNOLOGIES}

A number of lignin depolymerization methods (Figure 3) are proven to be commercially viable and currently performed on an industrial scale. Each method has unique advantages and disadvantages, together with challenges to overcome and the potential to be further improved (Chio et al., 2019).

\section{Thermal Depolymerization}

The main subtypes of thermal depolymerization include combustion, gasification, pyrolysis, and hydrothermal liquefaction (HTL). Compared to combustion and gasification under extremely high-temperature conditions, pyrolysis (especially fast/flash pyrolysis) and HTL have received tremendous interest as the baseline technologies for thermal depolymerization of lignin (Figure 4).

\section{Pyrolysis}

Pyrolysis is one of the most extensively studied and commercially applied techniques for lignin depolymerization. It refers to the heat treatment of lignin at relatively high temperatures under 
anoxic conditions, with or without catalysts (Agarwal et al., 2018). A temperature of $400^{\circ} \mathrm{C}$ is usually regarded as the critical point of lignin pyrolysis. Primary pyrolysis takes place at the temperature ranging from $200^{\circ} \mathrm{C}$ to $400^{\circ} \mathrm{C}$. At this stage, ether cleavage, especially $\alpha-\mathrm{O}-4$ and $\beta-\mathrm{O}-4$, accounts for most of the reactions. When the temperature is above $400^{\circ} \mathrm{C}$ (secondary pyrolysis), radical reactions become predominant and therefore result in an extensive rearrangement of the lignin structure. In this temperature range, C-C bonds cleavage occurs and leads to the formation of oligomers as well as monomers. Nevertheless, undesirable re-polymerization is also promoted under harsh reaction conditions, which is the main issue associated with thermal processing development (Li and Takkellapati, 2018).

By different heating rates and residence time, pyrolysis can be classified into conventional (or slow) pyrolysis and flash (or fast) pyrolysis (Laurichesse and Avérous, 2014). Concerning conventional pyrolysis, lignin is slowly heated to approximately $500^{\circ} \mathrm{C}$ with a relatively long residence time ranging from 5 to $30 \mathrm{~min}$ (Figueiredo et al., 2018). On the contrary, flash pyrolysis takes place at high temperatures between $600^{\circ} \mathrm{C}$ and $1,000^{\circ} \mathrm{C}$ with a much shorter residence time (0.5-5 s) (Figueiredo et al., 2018). The main product derived from conventional pyrolysis is a gaseous phase (syngas), while the flash pyrolysis technique is predominantly used to produce bio-oil, accounting for $60-75 \mathrm{wt} \%$ of the end products (Hoang et al., 2021). The mixture of end products from lignin pyrolysis includes monomeric and oligomeric phenols in liquid oil (e.g., phenol, catechol, syringol, and guaiacol), volatile products (e.g., methanol and acetone), gaseous compounds (e.g., $\mathrm{H}_{2}, \mathrm{CO}_{2}, \mathrm{CH}_{4}$, and $\mathrm{C}_{2} \mathrm{H}_{4}$ ) as well as biochar (Liu et al., 2015; Hoang et al., 2021). The yield and distribution of products are dependent on different sources of lignin and processing conditions (e.g., pyrolysis temperature, reactor type/heating rate, residence time, and feeding rate) (Fan et al., 2017; Figueiredo et al., 2018).

\section{Hydrothermal Liquefaction}

Hydrothermal liquefaction (HTL) is another baseline technology of lignin depolymerization which has been extensively explored in recent years. Different from other thermal depolymerization techniques such as pyrolysis and gasification, HTL is a better candidate for biomass with high water content because there is no need for preliminary drying processes, which are both energyintensive and costly (Kumar et al., 2017b). It is usually applied to obtain low-oxygen liquid bio-oil and/or phenolics (e.g., syringol, vanillin, guaiacol, as well as phenolic trimers to oligomers) (Cao et al., 2020) from lignin at high pressure (5-28 MPa) and relatively moderate temperature $\left(200-400^{\circ} \mathrm{C}\right)$ in a solvent with or without catalysts (Kang et al., 2013). In many cases, HTL of lignin is carried out in hot-compressed water ( $\mathrm{Li}$ and Takkellapati, 2018). Subcritical water $\left(\leq 374^{\circ} \mathrm{C}\right.$ and $\left.22 \mathrm{MPa}\right)$ behaves differently from water at room temperature and supercritical water $\left(\geq 374^{\circ} \mathrm{C}\right.$ and $\left.22 \mathrm{MPa}\right)$, and it has a few unique properties such as low viscosity and high solubility of organic compounds, making it a suitable reaction medium for biomass conversion. In other words, water serves not only as a green solvent but also as one of the reactants and catalysts in the lignin HTL process (Yang et al., 2020). Therefore, HTL is regarded as a sustainable and environmentally friendly technique for lignin depolymerization with less secondary pollution as well as a high conversion rate (Cao et al., 2018).

Many attempts have been made to investigate the depolymerization mechanism of lignin via HTL for the production of value-added aromatic derivatives. Hydrolysis of lignin into methoxy phenolics usually occurs first, followed by further hydrolysis of phenolics because ether bonds breakage requires less energy than C-C bonds (Singh et al., 2014). Cao et al. (2018) divided HTL of lignin depolymerization into three steps, including lignin hydrolysis, cleavage of ether bonds and C-C bonds among monomers, and the degradation of methoxy groups on benzene ring as well as the alkylation of functional groups on the benzene ring. In terms of critical parameters, the yield and distribution of products derived from lignin HTL are strongly dependent on temperature and reaction time while less dependent on other reaction parameters such as pressure and stirring speed of the reactor (Cao et al., 2018). It is reported that depolymerization of lignin and re-polymerization of intermediate products will be promoted simultaneously with the increase of temperature, leading to increases in both low-molecular-weight compounds and solid residue (Singh et al., 2014). Reaction time is an important parameter of lignin HTL that decides the nature of the end products. Long reaction times can increase the composition of low molecular end products by lignin HTL, with further prolonged reaction times inducing condensation of low molecular products into coke (Xu and Li, 2021). The heating rate is also identified as an important factor because the HTL process is kinetically controlled (Li and Takkellapati, 2018).

\section{Biological Depolymerization}

Biological depolymerization of lignin refers to the process of lignin degradation with the assistance of bacteria, fungi, or isolated enzymes under relatively mild conditions. Enzymatic depolymerization of lignin overlaps with fungi and bacteriaassisted depolymerization because many types of lignindegrading enzymes isolated from fungi and bacteria are used in vitro depolymerization of lignin (Chen and Wan, 2017). Therefore, biological depolymerization of lignin can be fundamentally considered as enzyme-assisted degradation in either in vitro or in vivo conditions.

The depolymerization rate by fungi ranges from $20 \%$ to nearly $100 \%$, depending on different lignin sources (Davis and Sello, 2010). Due to the biochemically versatile and efficient ligninolytic systems, white-rot and brown-rot fungi are highly promising degraders of lignin to produce various phenolic compounds such as vanillic acid, syringyl alcohol, and ferulic acid (Xu et al., 2018). However, the common drawbacks of fungus-mediated processes, especially poor adaptability toward temperature, $\mathrm{pH}$, and anoxic conditions, severely limit their applications in industries. In comparison with susceptible fungi, bacteria are much more tolerant to harsh conditions, and they would probably become a breakthrough in commercialized depolymerization or conversion of lignin. Several genera of bacteria that are most widely studied include Rhododococcus (e.g., R. Jostii RHA1), 
Pseudomonas, Streptomyces, Sphingomonas, as well as Nocardia (Xu et al., 2018).

Laccase, lignin peroxidase (LiP), manganese peroxidase $(\mathrm{MnP})$, versatile peroxidase (VP), and dye-decolorizing peroxidase $(\mathrm{DyP})$ are well-known enzymes for lignin degradation (Abdelaziz et al., 2016). Both laccase (lower redox potential) and peroxidase (higher redox potential) take advantage of the electron transfer mechanism to oxidize lignin structure and promote subsequent reactions by giving phenoxy radical or carbon-centered radical intermediates (Li and Takkellapati, 2018). Lignin peroxidase (LiP) is the first ligninolytic enzyme isolated from a white-rot fungus named Phanerochaete chrysosporium (Brown and Chang, 2014). LiP had high redox potential and was found to be specifically capable of breaking non-phenolic lignin units such as alkyl side chains by generating intermediate radicals (Abdelaziz et al., 2016; Chen and Wan, 2017). Different from LiP that attacks non-phenolic structures, $\mathrm{MnP}$ is proposed to be a degrader of phenolic structures. In terms of basic mechanism, $\mathrm{Mn}^{2+}$ is oxidized to $\mathrm{Mn}^{3+}$ as an electron donor in $\mathrm{MnP}$ and then chelated with dicarboxylic acids to become stabilized, after which chelated $\mathrm{Mn}^{3+}$ serves as a redox mediator that breaks non-phenolic units (Bugg and Rahmanpour, 2015). VP is a versatile lignin-degrading enzyme with nonspecific cleavage capability, which allows it to oxidize both low and high redox potential aromatic substrates (Chen and Wan, 2017). DyP is a newly discovered family of heme peroxidase, which uses $\mathrm{H}_{2} \mathrm{O}_{2}$ as an electron acceptor to promote the oxidation of a wide spectrum of the substrate (e.g., lignin model compounds, mono-phenolic compounds, and veratryl alcohol) (De Gonzalo et al., 2016; Chen and Wan, 2017). Among several types of ligninolytic enzymes, laccase is well-known for its strong versatility in the depolymerization of both phenolic and non-phenolic lignin structures. In contrast to other oxidases, laccase is more industrially attractive because it does not generate toxic $\mathrm{H}_{2} \mathrm{O}_{2}$ as a byproduct, and there's no need for the addition of cofactors (De Gonzalo et al., 2016). Mediators (or small molecules), which serve as redox shuttle between lignin structure and active sites on laccase, are necessary for lignin depolymerization (De Gonzalo et al., 2016).

In comparison with other lignin depolymerization technologies, which require high energy input and stringent conditions, biological depolymerization is identified as an ideal method due to its cost-effectiveness and specificity (Xu et al., 2018). Although the feasibility of biological depolymerization of lignin has been proved in many studies, more research efforts are required to address the common challenges of biological depolymerization, such as poor productivity and low yield prior to exploring potential industrial applications (Chen and Wan, 2017).

\section{Chemical Depolymerization}

As the name implies, chemical depolymerization refers to the process of lignin depolymerization by using different chemicals. Compared to severe thermal depolymerization (especially gasification and pyrolysis) and low-efficient biological depolymerization, chemical treatment of lignin has better control over the reaction and contributes to high product selectivity, which helps to unlock the full potential of lignin for renewable fuels and value-added chemicals production (Wang et al., 2013). In many cases, the chemical depolymerization of lignin is carried out in combination with thermal techniques, namely thermochemical depolymerization.

\section{Homogeneous Base/Acid Catalyzed Depolymerization}

Catalysis has been regarded as an indispensable technique in the lignin conversion process. The main advantages of catalytic lignin depolymerization are to accelerate the conversion and suppress the formation of undesirable products (e.g., char) while keeping the reaction conditions relatively mild. On the other hand, catalysts are also used to promote selective bond cleavage and therefore lead to the generation of specific value-added compounds or increase the ratio of desirable downstream products (Zhang and Wang, 2020).

Base-catalyzed depolymerization (BCD) of lignin is generally carried out under relatively harsh conditions (at the temperature above $300^{\circ} \mathrm{C}$ and high pressure over 200 bar), from which the most abundant products include catechol, syringol, and their derivatives (Wang et al., 2013; Xu et al., 2014). The basic mechanisms of BCD are the breakage of the aryl-alkyl bond (especially $\beta-\mathrm{O}-4$ bond), which usually requires a temperature higher than $270^{\circ} \mathrm{C}$ as well as the cleavage of functional groups (e.g., methoxy groups) attached to the aromatic rings (Wang et al., 2013; Xu et al., 2014). Toledano et al. (2012) conducted experiments on BCD of organosolv lignin (olive tree) for phenolic monomer production by using different base catalysts, including $\mathrm{KOH}, \mathrm{NaOH}, \mathrm{Ca}(\mathrm{OH})_{2}, \mathrm{LiOH}$, and $\mathrm{K}_{2} \mathrm{CO}_{3}$. The results suggested that base catalysts are capable of suppressing lignin repolymerization and char formation. In addition, it was observed that stronger bases, especially $\mathrm{NaOH}$ was able to produce more lignin-derived bio-oil than weaker bases such as $\mathrm{LiOH}$ (Toledano et al., 2012). Among a variety of different homogeneous base catalysts, $\mathrm{NaOH}, \mathrm{KOH}$, and $\mathrm{Na}_{2} \mathrm{CO}_{3}$ were the most extensively implemented in $\mathrm{BCD}$ reactions by researchers (Mahmood et al., 2013; Wang et al., 2013; Ahmad et al., 2018). It was reported that the formation of lignin-derived monomers was proportional to the concentration of $\mathrm{NaOH}$ in an aqueous solution (Roberts et al., 2011).

The harsh conditions required for $\mathrm{BCD}$ of lignin bring difficulties to product selectivity control and product purification, making acid-catalyzed lignin hydrolysis under mild conditions a better option for value-added chemical production (Xu et al., 2014). Similar to the BCD of lignin, acid-catalyzed lignin depolymerization also aims at the cleavage of $\beta-O-4$ bonds (Wang et al., 2013). The catalytic effects of different types of acids, including $\mathrm{HCl}, \mathrm{H}_{2} \mathrm{SO}_{4}$, $\mathrm{H}_{3} \mathrm{PO}_{4}$, and formic acid (FA), were investigated by Tayier and colleagues under mild microwave-assisted heating at the temperature of $160^{\circ} \mathrm{C}$. FA and $\mathrm{H}_{2} \mathrm{SO}_{4}$ were identified as decent catalysts for lignin depolymerization resulting in lower $\mathrm{M}_{\mathrm{w}}$ compounds and less solid residue in the product streams, while $\mathrm{H}_{3} \mathrm{PO}_{4}$ facilitated unfavorable re-polymerization (Tayier et al., 2017). More than 60wt\% yield of low-molecular-mass aromatics was reported by Rahimi et al. (2014), who carried 
out depolymerization of oxidized lignin under mild conditions in aqueous FA.

\section{Oxidative Depolymerization}

Oxidative depolymerization or oxidation is a promising possibility to expand the use of lignin due to the abundant hydroxyl groups in the lignin structure. Novel approaches in oxidative depolymerization of lignin are exploring the ability to conduct the depolymerization process under ambient conditions in cost-effective means (Ahmed et al., 2021). It is usually applied to produce phenolic derivatives by using oxidants that help to preserve the lignin aromatic rings, such as hydrogen peroxide, nitrobenzene, metallic oxide, and oxygen (Laurichesse and Avérous, 2014; Figueiredo et al., 2018). The reaction is usually associated with electron transfer or hydrogen atom extraction from lignin, resulting in a wide range of follow-up reactions such as hydroxylation of aromatic rings, phenol oxidation, benzylic oxidation, ring-opening reactions, and demethylation (Li and Takkellapati, 2018). The main products derived from oxidative depolymerization of lignin include aromatic aldehydes (e.g., vanillin and syringaldehyde) and their corresponding acids (e.g., vanillic acid and syringic acid) (Vangeel et al., 2018). Kraft lignin with high $\mathrm{C}-\mathrm{C}$ content is a suitable candidate for oxidative depolymerization because this technique is very effective in breaking C-C bonds (e.g., 5-5' and $\alpha-5$ ') ( $\mathrm{Li}$ and Takkellapati, 2018).

The reaction mechanism, product yield, and product distribution of lignin oxidation strongly depend on processing conditions, especially $\mathrm{pH}$ and oxidant selection. Many attempts have been made to investigate the oxidative depolymerization of lignin by hydrogen peroxide in both acidic and alkaline conditions. Xiang and Lee (2000) found that oxidative depolymerization of precipitated hardwood lignin (PHL) requires lower temperatures $\left(80-90^{\circ} \mathrm{C}\right)$ under strongly alkaline conditions while higher temperatures $\left(130-160^{\circ} \mathrm{C}\right)$ under acidic conditions to achieve the same degree of depolymerization (around 98wt\%). It is also worth noticing that formic acids, oxalic acids, and acetic acids are predominant components of product streams while only trace amounts of vanillin and syringaldehyde were detected, meaning that hydrogen peroxide may not be preferred if the desired product is aromatic aldehyde and corresponding acids (Xiang and Lee, 2000). Compared to hydrogen peroxide, nitrobenzene is considered a more effective oxidant to produce aldehydes (e.g., vanillin, syringaldehyde, and p-hydroxybenzaldehyde) and their respective acids (e.g., vanillic acid, syringic acid, and $p$-hydroxybenzoic acid) (Min et al., 2015). Min et al. (2015) also suggested that the maximum yield of a product derived from softwood and hardwood lignin by alkaline nitrobenzene oxidation could be achieved at a temperature of $170^{\circ} \mathrm{C}$ and a residence time of $2.5 \mathrm{~h}$. Sometimes metallic oxides and transition metals are used as alternative oxidants due to the carcinogenicity of nitrobenzene (Figueiredo et al., 2018).

\section{Ionic Liquid-Assisted Depolymerization}

Ionic liquids (ILs) are defined as substances composed of organic cations and inorganic/organic anions, which are in the liquid phase at or below $100^{\circ} \mathrm{C}$ (Xue et al., 2016). ILs have aroused much attention and were taken into considerations of lignin depolymerization in recent years due to their special properties. For instance, ILs have high potential in dissolving a wide range of biomass compared to other solvents, contributing to better utilization of bioresources (Hossain and Aldous, 2012). Although the dissolution mechanism of lignin in solvents remains unclear, a recent study showed that lignin dissolution by ILs is a function of a proton donating and accepting the ability of ILs (Akiba et al., 2017). Additionally, ILs exhibit extremely low vapor pressure due to their ionic nature, leading to the minimized release of volatile organic compounds (VOCs) (Dai et al., 2016; Zhu et al., 2018). On the other hand, the properties of IL (e.g., acidity, the solubility of catalyst, miscibility with solvents, and melting point) can be adjusted by a specific combination of cations and anions, making it a "designer solvent and/or catalyst" that is tailored to different reactions and processes (Cox et al., 2011; Zhu et al., 2018). IL is also well-known for its high thermal stability, recyclability, and non-flammability (Dai et al., 2016; Gillet et al., 2017).

Designs of efficient lignin depolymerization strategies should be based on a profound understanding of the properties of different ILs and the roles that various cations and anions play in the conversion process. It is reported that alkylsulfonate anions are most effective with respect to reducing the polydispersity or molecular weight and promoting the reaction activity of lignin, followed by lactates, acetates, chlorides, and phosphates (George et al., 2011). Targeted cleavage of $\beta-O-4$ linkages in lignin structure for guaiacol production has been extensively explored in the past several years, and the yield of breakage product in several ILs was found to follow the order $[\mathrm{Hmim}] \mathrm{Cl}>[\mathrm{Bmim}]\left[\mathrm{HSO}_{4}\right]$ $>[\mathrm{Hmim}] \mathrm{Br}>[\mathrm{Hmim}]\left[\mathrm{HSO}_{4}\right]>[\mathrm{Hmim}]\left[\mathrm{BF}_{4}\right]$ (Cox et al., 2011). Binder et al. (2009) found that weakly basic anions (e.g., [BF4 $\left.^{-},{ }^{-} \mathrm{CF} 3 \mathrm{SO} 3\right]^{-}$and $\left.[\mathrm{PF} 6]^{-}\right)$facilitated dealkylation while moderately basic anions (e.g., $\mathrm{Cl}^{-}, \mathrm{Br}^{-}$and $\left[\mathrm{CF}_{3} \mathrm{CO}_{2}\right]^{-}$) inhibited the unfavorable dealkylation reaction in targeted cleavage of ether bonds in lignin structure catalyzed by Brønsted acid (Binder et al., 2009).

The high cost of ILs severely limits the industrialized lignin depolymerization, which makes the recycling or reuse of ILs extremely important. In addition, product separation from ILs is necessitated by industrial chemical purification and reaction product analysis (Zakzeski et al., 2010). However, it's complicated to separate ILs with lignin-derived products without using organic solvents due to strong $\pi-\pi$ interactions between aromatic lignin structure and ILs (Hossain and Aldous, 2012; Wang et al., 2013). The currently available technologies applied to analyze dissolved lignin-derived products in ILs include ultravioletvisible (UV-vis) and infrared spectroscopy, mass spectrometry, light scattering techniques, and nuclear magnetic resonance (NMR) spectroscopy (Zakzeski et al., 2010). For the future application of ILs in lignin depolymerization, the ability to scale up, toxicity, and lifecycle analysis should also be taken into considerations (Stark, 2010; Weldemhret et al., 2020). 


\section{Microwave-Assisted Depolymerization}

Microwaves (MW) are high-frequency energy waves from the electromagnetic spectrum (300 MHz-300 GHz) (Wang et al., 2016). Dipolar rotation and ionic conduction are the two fundamental principles of microwave heating. When MW penetrates into organic molecules, the fluctuating electric field leads to extreme oscillation and realignment of dipoles as well as the migration of ions in the polar liquid. Consequently, friction is created inside the material as the source of internal energy, which causes the material to be heated up (Bundhoo, 2018). MW irradiation has received significant interest in recent years as an environmentally friendly, fast, energy-efficient, and costeffective technology for lignin depolymerization. In comparison with conventional heating technologies such as fast pyrolysis and hydrothermal liquefaction (HTL), MWassisted depolymerization exhibits several advantages such as energy-effectiveness, rapid heating, shorter reaction time requirement, improved product yield, high level of control as well as high selectivity (Bundhoo, 2018).

Lignin depolymerization with the assistance of MW is usually divided into two categories, which are $\mathrm{MW}$-assisted pyrolysis under relatively high temperature $\left(>400^{\circ} \mathrm{C}\right)$ and $\mathrm{MW}$-assisted solvolysis under mild conditions $\left(<200^{\circ} \mathrm{C}\right)$ (Wang et al., 2016; Dhar and Vinu, 2017). Although MW has been extensively applied in various chemical reactions, only a few papers on $\mathrm{MW}$-assisted lignin pyrolysis have been published. MW pyrolysis of alkali lignin catalyzed by activated carbon (AC) for renewable phenols was conducted by Bu et al. (2014). A central composite experimental design (CCD) was used to investigate the effects of reaction temperature and weight hourly space velocity (WHSV) on product yield and to optimize the reaction conditions. Phenols, guaiacols, hydrocarbons, and esters accounted for about $71-87 \%$ of biooils, and the maximum yield of phenolics was found at the temperature of $550^{\circ} \mathrm{C}$ and the WHSV of $2.18 \mathrm{~h}^{-1}$ (Bu et al., 2014). Farag et al. (2014) conducted experiments on MW pyrolysis of kraft lignin and tried to investigate the effects of nominal setting power $(1.5-2.7 \mathrm{~kW})$ and content of $\mathrm{MW}$ absorber (20-40wt\%) on product distribution and bio-oil composition. Regarding product distribution, aqueous phase, oil phase, non-condensable gas, and solid residue accounted for $17-21 \%, 15-20 \%, 21-27 \%$, and $32-40 \%$ of the product streams, respectively. Chemical compounds identified in the oil phase and the aqueous phase included phenols, guaiacols, catechols, and benzenes. The concentrations of phenols, guaiacols, and catechols in the oil phase were $74-108 \mathrm{mg} / \mathrm{g}$, $135-184 \mathrm{mg} / \mathrm{g}$, and $31-50 \mathrm{mg} / \mathrm{g}$, respectively (Farag et al., 2014).

As mentioned above, MW-assisted lignin solvolysis has attracted much attention as well because it can be conducted under moderate conditions. The effects of solvent type (ethylene glycol (EG), dimethyl sulfoxide (DMSO), and dimethyl formamide $(\mathrm{DMF}))$ and temperature $\left(100-140^{\circ} \mathrm{C}\right)$ on phenolic compounds production from $\mathrm{MW}$-assisted alkali lignin were reported by Dhar and Vinu (2017). The maximum yield of phenolics (approximately $20 \mathrm{wt} \%$ ) consisting of acetosyringone, guaiacol, syringaldehyde, anisole, and lignin dimers, was achieved at the temperature of $100^{\circ} \mathrm{C}$ in DMF and
DMSO. It's also worth noticing that high MW absorbing solvents such as EG and DMSO is favorable to obtain low $\mathrm{M}_{\mathrm{w}}$ products under mild conditions (Dhar and Vinu, 2017). The application of various catalysts such as metal nanoparticles, modified HUSY catalyst, ferric sulfate, $\mathrm{Pd} / \mathrm{C}$ with metal chloride, and organic/ inorganic acids on $\mathrm{MW}$-assisted lignin depolymerization were also reported (Dong et al., 2014; Toledano et al., 2014; Shen et al., 2015; Zhu et al., 2017; Shu et al., 2018).

At the current stage, high capital cost and application maturity are still the main obstacles for a wide application of $\mathrm{MW}$-assisted lignin depolymerization for value-added chemicals production. Although it has been proved that the combination of MW irradiation, catalysts, and organic solvents is capable of efficient lignin depolymerization, more efforts are required to develop low-cost or non-toxic catalysts and to optimize the conversion processes for large-scale production of ligninderived products, especially for nutraceutical and pharmaceutical applications.

\section{Lignin First-Biorefining Process}

Traditional biorefining methods of lignocellulosic biomass involve partial destruction of cell wall matrix and enzymatic conversion of cellulose and hemicellulose into sugars, generating a lignin-rich waste product (Sagues et al., 2018). Unlike traditional biorefining methods, lignin first-biorefining processes are capable of selective depolymerization of lignin and leaving cellulose and hemicellulose intact. Selective depolymerization of lignin from biomass prevents undesirable and irreversible condensation of lignin molecules during fractionation. Moreover, selective delignification eliminates the need for additional fractionation and purification steps, thus simplifying the operation and reducing production costs. Energy-intensive harsh fractionation methods used in traditional biorefining facilitate the cleave of $\beta-\mathrm{O}-4$ linkages and formation of $\mathrm{C}-\mathrm{C}$ bonds, producing condensed lignin difficult to depolymerize in subsequent biorefining steps (Galkin and Samec, 2016; Renders et al., 2017). Thus, lignin first-biorefining processes focus on adopting mild fractionation strategies to stabilize $\beta-\mathrm{O}-4$ linkages and active stabilization of lignin monomers and intermediates (during fractionation) to prevent condensation of lignin (Renders et al., 2017). Active stabilization of the lignin monomers and other intermediates can be directed to produce desired lignin structures during the fractionation process. Such stabilization approaches can directly deliver unique target chemical molecules during the fractionation step without the need for further chemical alterations (Galkin, 2021).

The mild fractionation methods commonly considered for the passive preservation of $\beta-\mathrm{O}-4$ linkages in lignin structure include ammonium-based fractionation, ionic-liquid assisted fractionation, $\gamma$-valerolactone-assisted hydrolysis, and mild organosolv techniques (Renders et al., 2017). Lignin can be isolated from biomass by dissolving in liquid ammonia. Liquid ammonium-based fractionation requires only mild conditions and is potent in solubilizing condensed/technical lignins. Liquid ammonia can solubilize lignin at room temperature under a pressure of 7-10 bars, instantly to within hours depending on 


\section{A Vanillin}<smiles>COc1cc(C=O)ccc1O</smiles>

B Syringaldehyde<smiles>COc1cc(C=O)cc(OC)c1O</smiles>

C Ferulic acid<smiles>COc1cc(/C=C/C(=O)O)ccc1O</smiles>

FIGURE 5 | Common low molecular weight aromatic chemical compounds produced by lignin depolymerization. (A) Vanillin, (B) Syringaldehyde, (C) Ferulic acid.

the nature of lignins (Strassberger et al., 2015). Like the liquid ammonium-based fractionation, organosolv fractionation utilizes organic solvents to dissolve lignin from the biomass and recover lignin while recycling solvents. Alcohols (e.g., ethanol and methanol), organic acids (e.g., acetic acid and formic acid), and combined solvents with catalysts are commonly used for organosolv fractionation of lignin (Thoresen et al., 2020). $\gamma$ Valerolactone can be used as a green fractionation organic solvent for the dissolution of lignin from biomass. Ahmed et al. (2020) had reported a lignin yield of 33\% for milled pine wood biomass when fractionation was performed with an $80 \%$ aqueous $\gamma$-valerolactone solution at $140-180^{\circ} \mathrm{C}$ temperature (Ahmed et al., 2020). The cosolvents significantly influence the dissolution of lignin by $\gamma$-valerolactone. Water is proven to be a more efficient cosolvent for $\gamma$-valerolactone to increase lignin solubility than ionic liquids, dimethyl sulfoxide, and dimethyl formaldehyde (Xue et al., 2016).

New methods of lignin-first biorefining focus on the active stabilization of lignin during biomass fractionation in addition to passive lignin stabilization by mild fractionation methods. Catalytic hydrogenolysis is the most studied lignin-first biorefining method, which combines lignin depolymerization coupled solvolytic extraction with reductive stabilization of intermediates (Cheng et al., 2018). Reductive catalytic fractionation (RCF), early-stage catalytic conversion of lignin (ECCL), catalytic upstream biorefining (CUB), and hydrogenolysis of protolignin are similar terms for catalytic hydrogenolysis of lignin with only slight alterations (Renders et al., 2017). Hydrogenolysis often occurs at the $\beta$-O-4 moieties cleaving $\mathrm{C}-\mathrm{O}$ bonds to generate lignin monomers and other intermediates. Catalytic hydrogenolysis of lignin is a reductive reaction that requires a metal catalyst such as $\mathrm{Pt}, \mathrm{Ru}, \mathrm{Rh}, \mathrm{Pd}$, and $\mathrm{Ni}$ (Cheng et al., 2018). The fractionation solvent (e.g., methanol) is primarily responsible for lignin extraction from biomass and depolymerization of solubilized lignin. The catalysts prevent the undesirable condensation of lignin by hydrogenation of reactive intermediates resulting from solvolytic depolymerization (Van den Bosch et al., 2017). Current research on lignin-first biorefining is focused on increasing the catalyst efficiency by use of bi-component catalyst systems (Wang et al., 2019), the discovery of reusable catalysts (Huang et al., 2018), and identifying the potential use of nanotechnology in catalyst development (Xiao et al., 2017).

\section{LIGNIN-DERIVED PRODUCTS AND POTENTIAL APPLICATIONS}

Lignin-derived organic products are sustainable substitutes for chemical products generated from petroleum refineries. The current and potential application of lignin can be divided into three categories, including 1) heat, power, green fuel, and syngas products; 2) macromolecules (e.g., biopolymers and nutraceuticals/drugs); and 3) low molecular weight aromatic chemical compounds from lignin depolymerization (Figure 5) (Holladay et al., 2007). Since the current research interest related to lignin mainly lies in its industrial applications as a renewable alternative to petroleum-based chemicals while the beneficial health applications are far less investigated, the emphasis of this section will be placed on the potential of lignin-derived products with special bioactive properties in food and pharmaceutical sectors, as well as in the area of human health.

\section{Low-Molecular-Weight Aromatic Compounds \\ Vanillin}

Among various aromatic monomers generated from lignin depolymerization, vanillin has been commercialized with an annual production of around 3,000 tons (Fache et al., 2016; Li and Takkellapati, 2018). Although the production of other biobased aromatics from lignin depolymerization has been intensely investigated, technology maturity is still relatively low (Lange et al., 2013). Vanillin (3-methoxy-4-hydroxybenzaldehyde) is one of the most widely used flavoring agents extracted from dried vanilla beans. As a plant secondary metabolite, isolated vanillin is a white to light yellow crystalline powder with a sweet and creamy vanilla-like odor (Priefert et al., 2001; Bezerra et al., 2016). Besides natural vanilla beans $(<1 \%)$ as a major source of commercial vanillin market, petroleum-based chemicals (roughly $85 \%$ ) and lignin (approximately 15\%) are two other important sources of synthetic/nature-identical vanillin (Agrawal et al., 2014; Fache 
et al., 2016). Considering the environmental sustainability and economic relevance, lignin is identified as a promising source of vanillin production compared to the other two sources. In the global market, about $60 \%$ of the industrial vanillin is used as a food additive, while the remaining $40 \%$ is used as cosmetic ingredients (approximately 33\%) and pharmaceuticals (roughly 7\%) (Bajpai, 2018).

In food industries, vanillin is widely found in sweet foods and beverages, especially ice cream, chocolate, confections, and baked goods (e.g., cakes and biscuits). Aside from the application in human foods, vanillin is used as a feed additive for poultry (e.g., chicken and turkey), cattle, and pigs, which provides desirable olfactive notes and promotes animal fattening (Mohammadi and Kim, 2018). On the other hand, vanillin is extensively used to produce other flavoring agents such as jasmine oil and zingiberene (ginger flavoring agent) (Banerjee and Chattopadhyay, 2018). Since vanillin exerts antioxidant and anti-microbial properties, it's used as a food preservative as well (Rupasinghe et al., 2006; Banerjee and Chattopadhyay, 2018). In the fragrance industry, vanillin is a common component of body lotions, shampoos, shower gels, soaps, room sprays, air fresheners, and candles.

Nowadays, the application of vanillin has been dramatically shifted from a flavoring and fragrance ingredient to an important intermediate/precursor for the synthesis of pharmaceuticals (e.g., L-dopa, dopamine, Aldomet, papaverine, and ftivazide), biobased polymers (e.g., thermoset and thermoplastic polymers) and fine chemicals (Fache et al., 2016; Tarabanko and Tarabanko, 2017). In the pharmaceutical industry, vanillin is usually used as a masking agent to mask the unpleasant flavor of pharmaceutical drugs (Van Wyk and Wink, 2014). It is also used to synthesize several pharmaceutical chemicals, including cyclovalone used as a digestant or choleretic, etamivan (ethamivan) as a stimulant for the nervous and respiratory system, levodopa (L-dopa) as an anti-Parkinson's disease agent, dopamine with anti-hypotensive effect, Aldomet (methyldopa) with anti-hypertensive effect, papaverine as a vasodilator and ftivazide for tuberculosis treatment (Bjørsvik and Liguori, 2002; Tarabanko and Tarabanko, 2017). Furthermore, the potential health-beneficial effects of vanillin itself have been reported by many researchers. For example, Tai et al., evaluated the antioxidant activity of vanillin by using multiple antioxidant assays and the experimental results indicated that vanillin exhibited a potent antioxidant effect in 2,2'-azino-bis (3ethylbenzothiazoline-6-sulphonic acid) radical cation/ABTS ${ }^{+}$ scavenging assay, oxygen radical absorbance capacity (ORAC) assay and oxidative hemolysis inhibition assay (OxHLIA) (Tai et al., 2011). It is widely believed that the presence of the hydroxyl group attached to an aromatic ring contributes to the antioxidant effect of vanillin (Bezerra et al., 2016). Rupasinghe et al. (2006) reported that vanillin effectively inhibited the growth of selected pathogenic, indicator, and spoilage microorganisms in vitro on fresh-cut apple slices, suggesting that vanillin could be a potential antimicrobial agent for refrigerated fruits and vegetables (Rupasinghe et al., 2006). A similar result was described by Rojas-Graü et al. (2007), who found that vanillin-containing coatings exhibited strong anti-microbial activity and prolonged the shelf-life of fresh-cut 'Fuji' apples (Rojas-Graü et al., 2007). In past studies, the antimutagenic activity of vanillin and vanillin derivatives has been assessed in different cell models (in vitro) and animal models (in vivo) with the presence or absence of chemical and physical mutagenic agents (Li et al., 2019; Ma et al., 2019; Sefi et al., 2019; Ghanim et al., 2021). Most of these studies indicate that vanillin is a pharmacological candidate to alleviate mutagenicity-associated diseases, especially cancers. The development of vanillin derivatives coupled with metals (e.g., $\mathrm{Ni}$ and Co.) as cancer therapeutics is one of the growing research interests (Kumar et al., 2017a; Kumar et al., 2021; Bahron et al., 2019).

Together with other lignin derivatives such as ferulic acid, guaiacol, syringaldehyde, and 4-hydroxybenzoic acid, vanillin (Figure 5A) is intensively investigated as a bio-based building block, and many efforts have been made by the scientific community to prepare a wide range of polymer products in recent years (Fache et al., 2015; Fache et al., 2016; Llevot et al., 2016). The hydroxyl and aldehyde reactive sites of vanillin structure provide opportunities for chemical modification to produce different monomers, which can be subsequently polymerized into value-added materials with diverse thermal and physical properties (Zhang et al., 2015). Characterized by rigid aromatic structures, vanillin and its derivatives (e.g., vanillic acid and vanillyl alcohol) are perfect candidates for the preparation of high-performance thermosetting materials, especially epoxy polymers, in which epoxy monomers with an aromatic structure bring stability to the network (Fache et al., 2015). The generated epoxy polymer can be employed in a broad spectrum of industrial fields such as construction, automotive, and aerospace with diverse applications such as adhesives and binders, paints and coatings, composites, electrical/electronic laminates, as well as flooring and paving (Auvergne et al., 2014). Vanillin and its derivatives are also high potentials for thermoplastics production, requiring aromatic monomers, especially polyesters with good thermal properties (Harvey et al., 2015). Apart from epoxy polymers and polyesters, other bio-based polymers generated from vanillin include phenolic resins, (meth)acrylic polymers, polyacetal, polyaldimines and polybenzoxazines, polymers from alkenes as well as polymers from the reductive coupling of aldehydes (Fache et al., 2015). These polymers can be further applied in insulators, furniture, packaging, containers, foams, etc. (Sun et al., 2018).

\section{Syringaldehyde}

Syringaldehyde (3,5-dimethoxy-4-hydroxybenzaldehyde) is another aromatic aldehyde of interest generated from lignin depolymerization. Similar to vanillin, syringaldehyde is used as an ingredient in the flavor and fragrance industry as well. Although syringaldehyde is far less commercialized as vanillin, it has become an emerging lignin-derived chemical, especially after the discovery of its role as an essential precursor of several pharmaceutical drugs used for the treatment of bacterial infection such as trimethoprim (3,4,5-trimethoxybenzaldehyde), Bactrim, and Biseptal (sulfamethoxazole or trimethoprim) (Tarabanko and Tarabanko, 2017; Ibrahim et al., 2012). Vanillin is also a precursor of trimethoprim synthesis, but syringaldehyde has the 
advantage of having two methoxyl groups (Figure 5B) (Mota et al., 2015). At the current stage, only preliminary in vitro tests have been carried out to identify the bioactive properties of syringaldehyde. Nevertheless, these valuable "cornerstones" are helpful for the identification of new potential research areas and the expanding application of syringaldehyde. For instance, Bountagkidou et al. (2010) found that syringaldehyde possesses exceptionally high antioxidant activity (peroxyl radical scavenging) compared to vanillin and protocatechuic aldehyde in crocin bleaching assay, which is an in vitro antioxidant assay. Syringaldehyde also exhibits anti-microbial activity against bacteria and fungi. It's reported that paper hand-sheets from pulps treated with monophenols such as syringaldehyde and acetosyringaldehyde exerted antibacterial activity against Staphylococcus aureus, Pseudomonas aeruginosa, and Klebsiella pneumonia, which can cause a wide range of human diseases (Fillat et al., 2012). González-Sarrías et al. (2012) evaluated the anti-cancer effect of 51 types of purified phenolic constituents isolated from Canadian maple syrup extract. The experimental results indicated that syringaldehyde and seven other phenolic compounds exhibited higher potential in suppressing the proliferation of colon cancer cells. These bioactive properties and potential health-beneficial effects suggested that syringaldehyde could be further examined as a food additive, natural health product (NHP), or pharmaceutical.

\section{Ferulic Acid}

Ferulic acid (FA, 4-hydroxy-3-methoxycinnamic acid, Figure 5C), belonging to the family of hydroxycinnamates, is also a common product of great value generated from lignin depolymerization. As a derivative of caffeic acid, FA is very abundant in fruits, vegetables, and beverages such as coffee and beer (Mancuso and Santangelo, 2014). Furthermore, it is an effective component of Chinese medicine herbs such as Cimicifuga heracleifolia (Shengma), Lignsticum (Chuanxiong/ Chinese lovage), and Angelica sinensis (Dong Quai/female ginseng) (Ou and Kwok, 2004). FA is also an important precursor of industrialized vanillin production (Kumar and Pruthi, 2014).

The methoxy, hydroxyl, and carboxylic acid groups on the benzene ring of FA (Figure 5C) provide opportunities for stabilization of phenoxyl radical intermediate and even termination of free radical chain reactions while reacting against a free radical (Ghosh et al., 2017). These functional groups make FA an efficient scavenger of both reactive oxygen species (ROS) and reactive nitrogen species (RNS) (Mancuso and Santangelo, 2014). In the food industry, FA can be used as a preservative due to its potent antioxidant property. The first use of FA as a food preservative to preserve orange and linseed oil was reported by a Japanese research team (Tsuchiya and Takasawa, 1975). Moreover, FA is an inhibitor of food discoloration that helps to prevent a color change of green tea and banana due to oxidation (Kumar and Pruthi, 2014). Since FA is a strong UV absorber and can be easily absorbed by the skin at acidic and neutral $\mathrm{pH}$, another application of FA is a cosmetic ingredient.

Besides its application as a food additive and cosmetic ingredient, FA is identified as an anti-diabetic agent, an anticancer agent, a neuroprotective agent, as well as a cardiovascular agent, considering its potential in the area of human health
(Parmar et al., 2015). It has been widely reported that FA effectively reduced the blood glucose level or alleviated the physical symptoms of diabetes (e.g., fattening) in induced diabetic animals (Sri Balasubashini et al., 2003; Ramar et al., 2012; Song et al., 2014). The main factors associated with cancer pathogenesis include enhanced cell proliferation, chronic inflammation, abnormal activation of pro-inflammatory pathways, free radical formation, and resulted in oxidative damage (Mancuso and Santangelo, 2014). In light of this, the ability of FA to scavenge free radicals, suppress cell proliferation, and activate cytoprotective enzymes in either in vitro or in vivo assays suggests that FA has the potential to play an adjuvant role in cancer therapy (Menter et al., 2010; Karthikeyan et al., 2011; Fahrioglu et al., 2016). Due to the discovery of anti-hypertensive and antihyperlipidemic properties by animal models, FA has its potential clinical use in cardiovascular diseases as well (Bumrungpert et al., 2018; Alam, 2019).

\section{Lignin-Derived Macromolecules}

In addition to low-molecular-weight aromatic compounds obtained from lignin depolymerization, macromolecular lignin derivatives also exhibit diverse therapeutic properties such as antiviral and anti-microbial activities, antitumor activities, obesity control, diabetes treatment as well as immunestimulatory effects (Barapatre, et al., 2016; Vinardell and Mitjans, 2017). However, the health-beneficial effects of ligninderived macromolecules are still far less investigated than that of tannins as a phyto-macromolecule, either in vitro assays or as animal feed supplements (Panzella and Napolitano, 2017).

\section{Lignin-Based Polymers/Lignophenols}

Lignophenols (LPs) are lignin-derived macromolecules produced experimentally from raw biomass by phase-separation systems, in which cellulose and hemicellulose of lignocellulosic are converted into hydrolyzed carbohydrates while lignin is converted into LPs (Sato et al., 2006; Lochab et al., 2014). Under hydrothermal conditions, these lignin-based polymers can be further converted into monophenols (e.g., phenol, catechol, syringol, and cresol) (Lochab et al., 2014). LPs are characterized by their high phenolic contents as well as high stabilities, and they exert a series of pharmacological activities (e.g., radical scavenging, neuroprotection, and diabetes control) (Lochab et al., 2014). Akao et al. (2004) examined the effects of various LPs isolated from bamboo lignin and reported that lignocresol, named lig-8, was a highly effective neuroprotector that prevented human neuroblastoma cells (SHSY-5Y) from abnormal apoptosis induced by hydrogen peroxide $\left(\mathrm{H}_{2} \mathrm{O}_{2}\right)$ and therefore delayed the progression of neurodegenerative diseases. The experimental results suggested that the neuroprotective effects of lig- 8 could be attributed to the scavenging of reactive oxygen species (ROS) and blocking of caspase activation, which was identified as an apoptosis executioner (Akao et al., 2004; Ito et al., 2007). Moreover, lig- 8 exhibited an anti-apoptotic effect by suppressing $\mathrm{H}_{2} \mathrm{O}_{2}$-induced dissipation of the mitochondrial membrane permeability transition (Akao et al., 2004). Similar results were obtained by many other researchers. Sato et al. (2006) found that LPs had an anti-apoptotic effect on 
pheochromocytoma (PC12) cells treated with an excessive amount of $\mathrm{Cu}$ and $\mathrm{Zn}$, which were highly associated with ROS generation and oxidative cell injury.

In terms of diabetes control, it's reported that LPs from beech tree (Fagus crenata Blume) played an active role in attenuating oxidative stress and inflammatory damage, activating macrophages as well as promoting glomerular expansion in the kidneys of streptozotocin (STZ)-induced diabetic rats (Sato et al., 2009). LPs-containing diets were proved to be very helpful for lowering plasma triglyceride levels in rats fed a high-fat diet by potentially suppressing the expression of sterol regulatory element-binding protein (SREBP) and acetyl-CoA carboxylase (ACC) (Sato et al., 2012). Mukai et al. (2011) also investigated the effects of lignin-derived LPs on diabetic rats, and their findings suggested that LPs alleviated vascular oxidative stress by inhibiting the expression of nicotinamide adenine dinucleotide (phosphate) $(\mathrm{NAD}(p) \mathrm{H})$ oxidase. Apart from the potential in diabetes control, Suzuki et al. (1990) found that LPs extracted from Lentinus edodes (an edible mushroom) have potent antiviral activity against human immunodeficiency virus (HIV) on the basis of the assay for the proliferation of mouse bone marrow cells. Although some health-beneficial effects of LPs have been demonstrated either in vitro or in vivo, their underlying physiological mechanisms remain unclear (Ito et al., 2006; Ito et al., 2007).

\section{Lignin-Carbohydrate Complex}

Lignin is rarely isolated as $100 \%$ purified materials and it is more or less associated with carbohydrate linkages (Zhao et al., 2020). Lignincarbohydrate complexes (LCCs) are major cell wall components formed by the dehydrogenation of three monolignols, as mentioned in the first section (Sakagami et al., 2010). Within plant biomass, more than $50 \%$ of lignin is linked to carbohydrates by covalent bonds, which severely restricts the separation of them in pulping and paper industry, as well as the efficient hydrolysis of raw lignocellulosic biomass for bioethanol production (You et al., 2015). Nevertheless, it's believed that this small amount of "impurity" (roughly $2-8 \%$ by weight) plays a critical role in the reactivity and properties of the macromolecule (Singh et al., 2005). Considering the potential health-beneficial effects of LCC, it displays diverse pharmacological activities as a macromolecular derivative of lignin, including anti-herpes activity, anti-HIV activity, anti-UV activity as well as anti-microbial activity.

Zhang et al. (2007) found that LCC prepared from Prunella vulgaris with a molecular weight of 8,500 exhibited in vivo antiherpes activity by suppressing viral binding and penetration based on viral binding assay and penetration assay (Zhang et al., 2007). Similar results were also reported by Lee et al. (2011) that LCC derived from Prunella vulgaris exerted anti-viral activity against herpes simplex virus, human cytomegalovirus (HCMV), and measles virus. These results suggested that Prunella vulgarisderived LCCs possessed potency as a functional ingredient against infectious diseases. As reported by Sakagami et al. (2011), LCC obtained from cacao (Thobroma cacao L.) mass, and cacao husk presented anti-HIV activity, indicating that LCCs could be further exploited as functional food ingredients with immunomodulatory and antiviral effects. The prominent anti-UV activity of LCCs extracted from Sasa senanensis Rehder leaves and Lentinus edodes Mycelia were also well documented, suggesting
LCCs could be included in Sun care products (Nanbu et al., 2011; Nanbu et al., 2013; Sakagami et al., 2016). Similar to other phenolic lignin fragments, LCC shows antifungal and antibacterial properties. For instance, Oh-Hara et al. (1990) found that LCC obtained from Pinus parviflora (Pine cones) exhibited anti-microbial activities against a series of microorganisms (e.g., Staphylococcal aureus, Escherichia coli, Pseudomonas aeruginosa, Klebsiella pneumoniae, Candida albicans, and Salmonella enteritidis) and protected mice from the lethal effects of microbial infection. Moreover, recent studies suggest that LCC can be effective against viruses. LCC isolated from beech wood through microwave acidolysis is effective against encephalomyocarditis virus. Decoupling of carbohydrate moieties from these LCC significantly suppresses the antiviral activity, emphasizing the importance of carbohydrate moieties on LCC for biological activities (Li et al., 2021).

\section{Lignin-Based Nanoparticles}

Since the large-scale application of lignin is limited by its poor solubility in water and complex macromolecule structure, conversion of raw lignin into aqueous nanoparticle dispersions with uniform shape and size is regarded as an enormous breakthrough (Lievonen et al., 2016; Chen et al., 2018). Recently, different nanomaterials have been successfully produced from lignin, including nanoparticles, nanofibers, nanotubes as well as nanogels by using different approaches such as interfacial crosslinking, antisolvent precipitation, solvent exchange, and sonication (Zhao et al., 2016; Figueiredo et al., 2018).

Nanoparticles usually exert improved or different properties in comparison to their bulk material or parent polymers due to higher surface-area-to-volume ratios (Yearla and Padmasree, 2015). Lu et al. (2012) reported that LNPs with a mean particle size of $144 \mathrm{~nm}$ obtained from organosolv lignin via supercritical antisolvent (SAS) process exhibited higher antioxidant and superoxide radical scavenging activities, as well as stronger reducing power than their non-nano scale counterparts. The experimental results suggested that LNPs could be further exploited in food processing industries, the pharmaceutical industry, and animal husbandry (Lu et al., 2012). A similar result was also reported by Yearla and Padmasree (2015) that LNPs with an average particle size of $104 \mathrm{~nm}$ prepared from dioxane lignin (DL) and alkali lignin (AL) by using the nanoprecipitation method had stronger antioxidant and UV-protective activities with reference to DL and AL, suggesting that LNPs is a promising candidate in food, cosmetic and pharmaceutical industries. Besides the potential application as an antioxidant, LNPs are also suitable for drug delivery and many other biomedical applications due to their biocompatibility, good stability, nontoxicity, capacity to load hydrophobic drugs and sustain their release. In addition, LNPs may allow the $\mathrm{pH}$-responsive release of drugs and possibly loading of hydrophilic drugs by adding $\mathrm{pH}$-sensitive polymers to them. Due to their special surface structure, LNPs can also be modified with targeting moieties, leading to increased cellular interaction with specific cells for disease therapy. As reported by Figueiredo et al. (2017), LNPs loaded with anti-cancer drugs exhibited antiproliferation effect in a series of cancer cells, 
TABLE 1 | Recent approaches to increase biomass delignification efficiency and generate target end products.

\section{Biomass Process conditions}

\section{Depolymerization method}

1) Microwave-assisted deep eutectic Pine wood solvents (DES)-based lignin depolymerization
Pine wood saw dust was fractionated in oxalic acid-choline chloride (1:1 M mass) and formic acid-choline chloride $(2: 1 \mathrm{M}$ mass) at $130^{\circ} \mathrm{C}$ for $15 \mathrm{~min}$ and $150^{\circ} \mathrm{C}$ for 15 min respectively. Saw dust: DES ratio was $5 \%$

\begin{tabular}{|c|c|c|}
\hline $\begin{array}{l}\text { 2) Lignin first-biorefining in the } \\
\text { presence of regenerable } \mathrm{Ru} / \mathrm{SiC} \\
\text { catalyst }\end{array}$ & Apple wood & $\begin{array}{l}\text { Apple wood was heated to } 250^{\circ} \mathrm{C} \text { for } 3 \mathrm{~h} \\
\left(1.6^{\circ} \mathrm{C} / \mathrm{min} \text { heating rate) in methanol under a }\right. \\
\text { working pressure of } 10.5 \mathrm{MPa} \text { while stirring } \\
\text { at } 700 \mathrm{rpm} \text {. Apple wood: methanol and } \mathrm{Ru} / \\
\mathrm{SiC} \text { catalyst: methanol ratios were } 5 \text { and } \\
0.75 \%(\mathrm{w} / \mathrm{v}) \text { respectively }\end{array}$ \\
\hline
\end{tabular}

3) Catalysts-based lignin

$\begin{array}{ll}\text { Alkali lignin (kraft } & \text { Alkali lignin was heated to } 260^{\circ} \mathrm{C} \text { for } 5 \mathrm{~h} \\ \text { lignin) } & \left(4^{\circ} \mathrm{C} / \mathrm{min} \text { heating rate) in methanol (initial }\right. \\ & \text { system pressure } 4 \mathrm{MPa}) \text { in the presence of }\end{array}$ depolymerization for the regulation of lignin) final product output system pressure $4 \mathrm{MPa}$ ) in the presence of catalysts $\mathrm{Pd} / \mathrm{C}$ and a metal chloride (e.g., $\mathrm{ZnCl}_{2}$ ). Lignin: methanol and $\mathrm{Pd} / \mathrm{C}$ : methanol ratios were 1.25 and $0.25 \%(\mathrm{w} / \mathrm{v})$ respectively. The concentration of metal chloride catalyst was $0.5 \mathrm{mmol}$

4) Continuous acid-catalyzed lignin Maple wood
depolymerization
depolymerization thermal treatment of maple wood $(5 \% \mathrm{w} / \mathrm{w})$
Initially, maple wood lignin was obtained by at $250^{\circ} \mathrm{C}$ for $30 \mathrm{~min}$ with fractionation solvent; $\gamma$-valerolactone $(80 \% \mathrm{w} / \mathrm{w})$, water $(19 \% \mathrm{w} / \mathrm{w})$, and sulfuric acid $(1 \% \mathrm{w} / \mathrm{w})$. Extracted lignin was subjected to continuous depolymerization for $48 \mathrm{~h}$ by flowing over $\mathrm{Zr}-\mathrm{KIT}-5$ catalyst at $250^{\circ} \mathrm{C}$ and 1,000 rpm. The continuous flow of lignin into the reactor was achieved by dissolving lignin $(1 \% \mathrm{w} / \mathrm{w})$ in $\gamma$-valerolactone

\begin{abstract}
5) Delignification by peroxidase activity mimicking cerium doped iron oxide nano particles
\end{abstract}

Corn cobs

Corn cobs were delignified in distilled water mixed with $\mathrm{H}_{2} \mathrm{O}_{2}(0.1 \mathrm{M})$ and cerium doped iron oxide nano particles $(2 \mathrm{~g} / \mathrm{L})$. Delignification was performed in a shaking incubator $(200 \mathrm{rpm})$ at $25^{\circ} \mathrm{C}$. Biomass: reaction solvent ratio was 15\% (w/v)

6) Organosolv fractionation of biomass in the presence of sodium dithionite
Silver birch wood (milled and dried) The biomass was fractionated in $\mathrm{n}$-butanolwater $(1: 1 \mathrm{v} / \mathrm{v})$ reaction solvent mixed with sodium dithionate $(0.83 \% \mathrm{w} / \mathrm{v})$ under an initial pressure of 30 bars. Fractionation reaction was performed at $200^{\circ} \mathrm{C}\left(10^{\circ} \mathrm{C} / \mathrm{min}\right.$ heating rate) for $3 \mathrm{~h}$ while stirring at 750 rpm. Biomass: reaction solvent ratio was $29 \% \mathrm{w} / \mathrm{v}$

\begin{tabular}{ll}
\hline $\begin{array}{l}\text { 7) Catalyst based lignin } \\
\text { depolymerization }\end{array}$ & Poplar wood \\
& wood by heating with ethanol-water $(60 / 40 \quad$ Low molecular lignin fragments (87\%) and \\
& $\mathrm{v} / \mathrm{v})$ at $205^{\circ} \mathrm{C}$ as described by Guo et al. \\
& $(2015)$. Extracted lignin $(2.5 \mathrm{w} / \mathrm{v})$ was \\
& depolymerized in supercritical ethanol- \\
& water $(1: 1 \mathrm{v} / \mathrm{v})$ solvent in the presence of \\
& novel $10 \% \mathrm{Ni} /$ lignin-based carbon nanofiber \\
& catalyst $(0.5 \% \mathrm{w} / \mathrm{v})$. Reaction conditions \\
& were $300^{\circ} \mathrm{C}$ for $5 \mathrm{~h}$ with stirring
\end{tabular}

C, carbon; DES, deep eutectic solvents; $\mathrm{H}_{2} \mathrm{O}_{2}$, hydrogen peroxide; $\mathrm{MPa}$, mega pascal; Ni, nickel; Pd, palladium; rpm, rounds per minute; Ru, ruthenium; Si, silicon; ZnCl 2 , zinc chloride.

including breast cancer cells (MDA-MB-231 and MCF-7), prostate cancer endothelial cells (PC3-MM2), and colon cancer cells (Caco-2).
A mixture of depolymerized lignin with different Muley et al. molecular weights. Lignin recovery was (2019) over $80 \%$
The catalyzed-based reaction generated a Shu et al. mixture of phenols and guaiacols. Interestingly, (2018) the choice of metal chloride catalyst altered the proportion between phenols and guaiacols. $\mathrm{ZnCl}_{2}$ increased the proportion of guaiacols and $\mathrm{CrCl}_{3}$ increased the proportion of phenols in the final depolymerized lignin mixture

\section{A mixture of guaiacol, syringol, and phenolics. Nandiwale Continuous depolymerization of lignin et al., 2020 significantly improved the monomeric yield $(7 \%$ wt) in the presence of Zr-KIT-5 catalyst

A number of lignin degradation intermediated were generated during this delignification process, including, phenolic acids, simple sugars, fatty acid methyl esters, aromatic alcohols, and aldehydes. The maximum lignin degradation was $44 \% \mathrm{wt}$

Lignin oil and monophenolics. The detected monophenols were 4-ethoxy-3,5-

Brienza et al. dimthylbenzaldehyde, 4-propenyl syringol, desaspidinol, and acetosyringone
Rajak et al. (2021) 
stability, and barrier properties (Nair et al., 2014; Beisl et al., 2017). This special characteristic allows LNPs to be exploited as reinforcing agents in nanocomposites and polymer matrices.

\section{OUTLOOK: OPPORTUNITIES AND CHALLENGES FOR LIGNIN USE IN BIOREFINERY INDUSTRY}

Similar to a contemporary petroleum refinery, the concept of biorefinery emerged in the 1990s for maximizing the value of biomass by integrating biomass conversion processes and advanced equipment to produce biofuel, syngas, power, and high-value chemicals (Yuan et al., 2013; Li and Takkellapati, 2018). As a natural biopolymer, lignin offers significant opportunities for enhanced operation of the lignocellulosic biorefinery industry due to its abundance, chemical versatility (functional groups), biodegradability, biocompatibility, reinforcing capability, antioxidant properties as well as potential pharmacological activities. Using lignin for heat, power, syngas, and green fuel generation is an intermediate near-term opportunity for the biorefinery industry. Apart from the near-term opportunity, almost all current commercial uses of lignin take advantage of its polymer and polyelectrolyte properties. Based on this medium-term opportunity, one of the main targets of the use of lignin in the biorefinery industry is to produce macromolecules with relatively low value and limited applications, including binders, dispersants, emulsifiers, and sequestrants. The production of high-value polymers and macro-monomer such as carbon fibers and thermosetting resins significantly expand the commercial applications of lignin with the development of selective conversion processes assisted by "tailored" catalysts and solvents. At the current stage, obtaining aromatic chemicals of great value (e.g., BTX chemicals and monomer molecules) efficiently from lignin via depolymerization has become a long-term opportunity, which is regarded as challenging but feasible.

Current studies on lignin depolymerization are primarily focused on increasing the biomass delignification efficiency and generating specific end products (Table 1). The use of novel catalysts in conventional and lignin first-biorefining techniques is of central interest to improve lignin depolymerization efficiency and increase the proportion of target products in depolymerized product mixture (Huang et al., 2018; Shu, et al., 2018). The application of nanotechnology for lignin depolymerization can significantly improve lignin degradation efficiency (Du et al., 2020). Novel cerium doped iron oxide nano particle catalyst developed by Rajak et al. (2021) was able to mimic peroxidase activity and directly degrade lignin from corn cobs into a mixture of low molecular products. This lignin degradation process required only low operation temperatures $\left(25^{\circ} \mathrm{C}\right)$ to reach $44 \%$ (wt) degradation of lignin within $30 \mathrm{~h}$ (Rajak et al., 2021). Continuous lignin depolymerization systems equipped with catalysts can be used to increase the lignin degradation efficiency (Nandiwale et al., 2020). However, low biomass to the solvent ratio (w/v) might bring challenges in the economic upscaling of these methods to an industrial scale. The metal catalysts used for lignin depolymerization have a significant influence on the proportions of end products (Shu et al., 2018). Further studies to formulate catalysts capable of delivering target end products can eliminate the requirement for additional purification steps and bring down the cost of production.

Together with significant opportunities, lignin use within the biorefinery industry brings about a series of challenges. The complex structure, high molecular weight, and uncertain chemical properties and reactivity severely restrict the hightech applications of lignin. Additionally, the physicochemical properties of lignin (e.g., solubility, reactivity, molecular weight distribution, and a number of functional groups) are constantly varying with its origins/biomass source and different lignin recovery processes. The variability of lignin will naturally result in mixtures of products, and it will be challenging and less economically feasible to isolate and purify all different compounds for further applications. On the other hand, identifying the optimal technologies to separate lignin from raw biomass and depolymerize isolated lignin into valueadded products requires a sophisticated technical and economic analysis and a profound understanding of every conversion process in lignin biorefinery and the life cycle of lignin-derived products, from upstream to downstream. These challenges have not yet been fully addressed. Due to the multifunctional nature of lignin, depolymerized lignin generates a mixture of different product streams, which requires costly separation and purification processes. For example, depolymerized products such as hydroxybenzoates and their derivatives can be used in multiple uses in food, NHP, cosmetic, and pharmaceutical industries; however, assessment of their safety and bio-efficacy is required. Future research efforts should focus on each product stream's distinct challenges. Additionally, engineering plant feedstocks for tuning lignin monomer and tailoring functionality might help mitigate these challenges. Future research could also discover to what extent the lignin structure in plants could be altered for yet to be recognized new applications of humanity.

\section{AUTHOR CONTRIBUTIONS}

NZ and WT have written the draft manuscript. QH and HR edited the manuscript. All the co-authors reviewed and approved the final version of the manuscript.

\section{FUNDING}

The authors (QH and HR) would like to recognize the financial support provided by the Discovery Grants of the Natural Sciences and Engineering Research Council (NSERC) of Canada. Grant numbers: RGPIN-2020-05695 (QH) and RGPIN-201605369 (HR). 


\section{REFERENCES}

Abdelaziz, O. Y., Brink, D. P., Prothmann, J., Ravi, K., Sun, M., García-Hidalgo, J., et al. (2016). Biological Valorization of Low Molecular Weight Lignin. Biotechnol. Adv. 34 (8), 1318-1346. doi:10.1016/j.biotechadv.2016.10.001

Agarwal, A., Rana, M., and Park, J.-H. (2018). Advancement in Technologies for the Depolymerization of Lignin. Fuel Process. Technol. 181, 115-132. doi:10.1016/j.fuproc.2018.09.017

Agrawal, A., Kaushik, N., and Biswas, S. (2014). Derivatives and Applications of Lignin - an Insight. Scitech J. 1 (7), 30-36.

Ahmad, Z., Mahmood, N., Yuan, Z., Paleologou, M., and Xu, C. (2018). Effects of Process Parameters on Hydrolytic Treatment of Black Liquor for the Production of Low-Molecular-Weight Depolymerized Kraft Lignin. Molecules 23 (10), 2464. doi:10.3390/molecules23102464

Ahmad, Z., Paleologou, M., and Xu, C. C. (2021). Oxidative Depolymerization of Lignin Using Nitric Acid under Ambient Conditions. Ind. Crops Prod. 170, 113757. doi:10.1016/j.indcrop.2021.113757

Ahmed, M. A., Lee, J. H., Raja, A. A., and Choi, J. W. (2020). Effects of GammaValerolactone Assisted Fractionation of ball-milled pine wood on Lignin Extraction and its Characterization as Well as its Corresponding Cellulose Digestion. Appl. Sci. 10 (5), 1599. doi:10.3390/app10051599

Akao, Y., Seki, N., Nakagawa, Y., Yi, H., Matsumoto, K., Ito, Y., et al. (2004). A Highly Bioactive Lignophenol Derivative from Bamboo Lignin Exhibits a Potent Activity to Suppress Apoptosis Induced by Oxidative Stress in Human Neuroblastoma SH-Sy5y Cells. Bioorg. Med. Chem. 12 (18), 4791-4801. doi:10.1016/j.bmc.2004.07.022

Akiba, T., Tsurumaki, A., and Ohno, H. (2017). Induction of Lignin Solubility for a Series of Polar Ionic Liquids by the Addition of a Small Amount of Water. Green. Chem. 19 (9), 2260-2265. doi:10.1039/c7gc00626h

Alam, M. A. (2019). Anti-hypertensive Effect of Cereal Antioxidant Ferulic Acid and its Mechanism of Action. Front. Nutr. 6, 121. doi:10.3389/fnut.2019.00121

Auvergne, R., Caillol, S., David, G., Boutevin, B., and Pascault, J.-P. (2014). Biobased Thermosetting Epoxy: Present and Future. Chem. Rev. 114 (2), 1082-1115. doi:10.1021/cr3001274

Bahron, H., Khaidir, S. S., Tajuddin, A. M., Ramasamy, K., and Yamin, B. M. (2019). Synthesis, Characterization and Anticancer Activity of Mono- and Dinuclear $\mathrm{Ni}(\mathrm{II})$ and $\mathrm{Co}(\mathrm{II})$ Complexes of a Schiff Base Derived from O-Vanillin. Polyhedron 161, 84-92. doi:10.1016/j.poly.2018.12.055

Bajpai, P. (2018). "Value-added Products from Lignin," in Biotechnology for Pulp and Paper Processing (Singapore: Springer), 561-571. doi:10.1007/978-981-107853-8_25

Banerjee, G., and Chattopadhyay, P. (2018). Vanillin Biotechnology: The Perspectives and Future. J. Sci. Food Agric. 99 (2), 499-506. doi:10.1002/ jsfa.9303

Barapatre, A., Meena, A. S., Mekala, S., Das, A., and Jha, H. (2016). In Vitro evaluation of Antioxidant and Cytotoxic Activities of Lignin Fractions Extracted from Acacia Nilotica. Int. J. Biol. Macromolecules 86, 443-453. doi:10.1016/j.ijbiomac.2016.01.109

Beisl, S., Friedl, A., and Miltner, A. (2017). Lignin from Micro- to Nanosize: Applications. Int. J. Mol. Sci. 18 (11), 2367. doi:10.3390/ijms18112367

Bezerra, D. P., Soares, A. K., and De Sousa, D. P. (20162016). Overview of the Role of Vanillin on Redox Status and Cancer Development. Oxid Med. Cel Longev 2016, 9734816. doi:10.1155/2016/9734816

Binder, J. B., Gray, M. J., White, J. F., Zhang, Z. C., and Holladay, J. E. (2009). Reactions of Lignin Model Compounds in Ionic Liquids. Biomass and Bioenergy 33 (9), 1122-1130. doi:10.1016/j.biombioe.2009.03.006

Bjørsvik, H., and Liguori, L. (2002). Organic Processes to Pharmaceutical Chemicals Based on Fine Chemicals from Lignosulfonates. Org. Process Res. Develop. 6 (3), 279-290.

Börcsök, Z., and Pásztory, Z. (2021). The Role of Lignin in wood Working Processes Using Elevated Temperatures: An Abbreviated Literature Survey. Eur. J. Wood Prod. 79 (3), 511-526. doi:10.1007/s00107-020-01637-3

Bountagkidou, O. G., Ordoudi, S. A., and Tsimidou, M. Z. (2010). Structureantioxidant Activity Relationship Study of Natural Hydroxybenzaldehydes Using In Vitro Assays. Food Res. Int. 43 (8), 2014-2019. doi:10.1016/ j.foodres.2010.05.021
Brienza, F., Van Aelst, K., Thielemans, K., Sels, B. F., Debecker, D. P., and Cybulska, I. (2021). Enhancing Lignin Depolymerization via a Dithionite-Assisted Organosolv Fractionation of Birch Sawdust. Green. Chem. 23 (9), 3268-3276. doi:10.1039/d1gc00503k

Brown, M. E., and Chang, M. C. (2014). Exploring Bacterial Lignin Degradation. Curr. Opin. Chem. Biol. 19 (1), 1-7. doi:10.1016/ j.cbpa.2013.11.015

Bu, Q., Lei, H., Wang, L., Wei, Y., Zhu, L., Zhang, X., et al. (2014). Bio-based Phenols and Fuel Production from Catalytic Microwave Pyrolysis of Lignin by Activated Carbons. Bioresour. Technol. 162, 142-147. doi:10.1016/ j.biortech.2014.03.103

Bugg, T. D., and Rahmanpour, R. (2015). Enzymatic Conversion of Lignin into Renewable Chemicals. Curr. Opin. Chem. Biol. 29 (C), 10-17. doi:10.1016/ j.cbpa.2015.06.009

Bumrungpert, A., Lilitchan, S., Tuntipopipat, S., Tirawanchai, N., and Komindr, S. (2018). Ferulic Acid Supplementation Improves Lipid Profiles, Oxidative Stress, and Inflammatory Status in Hyperlipidemic Subjects: A Randomized, DoubleBlind, Placebo-Controlled Clinical Trial. Nutrients 10 (6), 713. doi:10.3390/ nu10060713

Bundhoo, Z. M. A. (2018). Microwave-assisted Conversion of Biomass and Waste Materials to Biofuels. Renew. Sustain. Energ. Rev. 82 (P1), 1149-1177. doi:10.1016/j.rser.2017.09.066

Cao, L., Yu, I. K. M., Liu, Y., Ruan, X., Tsang, D. C. W., Hunt, A. J., et al. (2018). Lignin Valorization for the Production of Renewable Chemicals: State-Of-TheArt Review and Future Prospects. Bioresour. Technol. 269, 465-475. doi:10.1016/j.biortech.2018.08.065

Cao, Y., Zhang, C., Tsang, D. C. W., Fan, J., Clark, J. H., and Zhang, S. (2020). Hydrothermal Liquefaction of Lignin to Aromatic Chemicals: Impact of Lignin Structure. Ind. Eng. Chem. Res. 59 (39), 16957-16969. doi:10.1021/ acs.iecr.0c01617

Chen, L., Zhou, X., Shi, Y., Gao, B., Wu, J., Kirk, T. B., et al. (2018). Green Synthesis of Lignin Nanoparticle in Aqueous Hydrotropic Solution toward Broadening the Window for its Processing and Application. Chem. Eng. J. 346, 217-225. doi:10.1016/j.cej.2018.04.020

Chen, Z., and Wan, C. (2017). Biological Valorization Strategies for Converting Lignin into Fuels and Chemicals. Renew. Sustain. Energ. Rev. 73, 610-621. doi:10.1016/j.rser.2017.01.166

Cheng, C., Shen, D., Gu, S., and Luo, K. H. (2018). State-of-the-art Catalytic Hydrogenolysis of Lignin for the Production of Aromatic Chemicals. Catal. Sci. Technol. 8 (24), 6275-6296. doi:10.1039/c8cy00845k

Chio, C., Sain, M., and Qin, W. (2019). Lignin Utilization: a Review of Lignin Depolymerization from Various Aspects. Renew. Sustain. Energ. Rev. 107, 232-249. doi:10.1016/j.rser.2019.03.008

Cox, B. J., Jia, S., Zhang, Z. C., and Ekerdt, J. G. (2011). Catalytic Degradation of Lignin Model Compounds in Acidic Imidazolium Based Ionic Liquids: Hammett Acidity and Anion Effects. Polym. Degrad. Stab. 96 (4), 426-431. doi:10.1016/j.polymdegradstab.2011.01.011

Dai, J., Patti, A. F., and Saito, K. (2016). Recent Developments in Chemical Degradation of Lignin: Catalytic Oxidation and Ionic Liquids. Tetrahedron Lett. 57 (45), 4945-4951. doi:10.1016/j.tetlet.2016.09.084

Davis, J. R., and Sello, J. K. (2010). Regulation of Genes in Streptomyces Bacteria Required for Catabolism of Lignin-Derived Aromatic Compounds. Appl. Microbiol. Biotechnol. 86 (3), 921-929. doi:10.1007/ s00253-009-2358-0

De Gonzalo, G., Colpa, D. I., Habib, M. H. M., and Fraaije, M. W. (2016). Bacterial Enzymes Involved in Lignin Degradation. J. Biotechnol. 236 (C), 110-119. doi:10.1016/j.jbiotec.2016.08.011

Dhar, P., and Vinu, R. (2017). Understanding Lignin Depolymerization to Phenols via Microwave-Assisted Solvolysis Process. J. Environ. Chem. Eng. 5 (5), 4759-4768. doi:10.1016/j.jece.2017.08.031

Dong, C., Feng, C., Liu, Q., Shen, D., and Xiao, R. (2014). Mechanism on Microwave-Assisted Acidic Solvolysis of Black-Liquor Lignin. Bioresour. Technol. 162, 136-141. doi:10.1016/j.biortech.2014.03.060

Du, B., Liu, C., Wang, X., Han, Y., Guo, Y., Li, H., et al. (2020). Renewable LigninBased Carbon Nanofiber as Ni Catalyst Support for Depolymerization of Lignin to Phenols in Supercritical Ethanol/water. Renew. Energ. 147, 1331-1339. doi:10.1016/j.renene.2019.09.108 
Fache, M., Boutevin, B., and Caillol, S. (2016). Vanillin Production from Lignin and its Use as a Renewable Chemical. ACS Sustain. Chem. Eng. 4 (1), 35-46. doi:10.1021/acssuschemeng.5b01344

Fache, M., Boutevin, B., and Caillol, S. (2015). Vanillin, a Key-Intermediate of Biobased Polymers. Eur. Polym. J. 68 (C), 488-502. doi:10.1016/ j.eurpolymj.2015.03.050

Fahrioğlu, U., Dodurga, Y., Elmas, L., and Seçme, M. (2016). Ferulic Acid Decreases Cell Viability and colony Formation while Inhibiting Migration of MIA PaCa-2 Human Pancreatic Cancer Cells In Vitro. Gene 576 (1), 476-482. doi:10.1016/j.gene.2015.10.061

Fan, L., Zhang, Y., Liu, S., Zhou, N., Chen, P., Cheng, Y., et al. (2017). Bio-oil from Fast Pyrolysis of Lignin: Effects of Process and Upgrading Parameters. Bioresour. Technol. 241, 1118-1126. doi:10.1016/j.biortech.2017.05.129

Farag, S., Fu, D., Jessop, P. G., and Chaouki, J. (2014). Detailed Compositional Analysis and Structural Investigation of a Bio-Oil from Microwave Pyrolysis of Kraft Lignin. J. Anal. Appl. Pyrolysis 109 (C), 249-257. doi:10.1016/ j.jaap.2014.06.005

Feghali, E., van de Pas, D. J., Parrott, A. J., and Torr, K. M. (2020). Biobased Epoxy Thermoset Polymers from Depolymerized Native Hardwood Lignin. ACS Macro Lett. 9 (8), 1155-1160. doi:10.1021/acsmacrolett.0c00424

Feofilova, E. P., and Mysyakina, I. S. (2016). Lignin: Chemical Structure, Biodegradation, and Practical Application (A Review). Appl. Biochem. Microbiol. 52 (6), 573-581. doi:10.1134/s0003683816060053

Figueiredo, P., Lintinen, K., Hirvonen, J. T., Kostiainen, M. A., and Santos, H. A. (2018). Properties and Chemical Modifications of Lignin: Towards LigninBased Nanomaterials for Biomedical Applications. Prog. Mater. Sci. 93, 233-269. doi:10.1016/j.pmatsci.2017.12.001

Figueiredo, P., Lintinen, K., Kiriazis, A., Hynninen, V., Liu, Z., Bauleth-Ramos Santos, T. H. A., et al. (2017). In Vitro evaluation of Biodegradable Lignin-Based Nanoparticles for Drug Delivery and Enhanced Antiproliferation Effect in Cancer Cells. Biomaterials 121, 97-108. doi:10.1016/j.biomaterials.2016.12.034

Fillat, A., Gallardo, O., Vidal, T., Pastor, F. I. J., Díaz, P., and Roncero, M. B. (2012). Enzymatic Grafting of Natural Phenols to Flax Fibres: Development of Antimicrobial Properties. Carbohydr. Polym. 87 (1), 146-152. doi:10.1016/ j.carbpol.2011.07.030

Galkin, M. (2021). From Stabilization Strategies to Tailor-Made Lignin Macromolecules and Oligomers for Materials. Curr. Opin. Green Sustain. Chem. 28, 100438. doi:10.1016/j.cogsc.2020.100438

Galkin, M. V., and Samec, J. S. M. (2016). Lignin Valorization through Catalytic Lignocellulose Fractionation: A Fundamental Platform for the Future Biorefinery. ChemSusChem 9 (13), 1544-1558. doi:10.1002/cssc.201600237

George, A., Tran, K., Morgan, T. J., Benke, P. I., Berrueco, C., Lorente, E., et al. (2011). The Effect of Ionic Liquid Cation and Anion Combinations on the Macromolecular Structure of Lignins. Green. Chem. 13 (12), 3375-3385. doi:10.1039/c1gc15543a

Ghanim, A. M. H., Younis, N. S., and Metwaly, H. A. (2021). Vanillin Augments Liver Regeneration Effectively in Thioacetamide Induced Liver Fibrosis Rat Model. Life Sci. 286, 120036. doi:10.1016/j.lfs.2021.120036

Ghosh, S., Basak, P., Dutta, S., Chowdhury, S., and Sil, P. C. (2017). New Insights into the Ameliorative Effects of Ferulic Acid in Pathophysiological Conditions. Food Chem. Toxicol. 103, 41-55. doi:10.1016/j.fct.2017.02.028

Gillet, S., Aguedo, M., Petitjean, L., Morais, A. R. C., Da Costa Lopes, A. M., Łukasik, R. M., et al. (2017). Lignin Transformations for High Value Applications: Towards Targeted Modifications Using green Chemistry. Green. Chem. 19 (18), 4200-4233. doi:10.1039/c7gc01479a

González-Sarrías, A., Li, L., and Seeram, N. P. (2012). Anticancer Effects of maple Syrup Phenolics and Extracts on Proliferation, Apoptosis, and Cell Cycle Arrest of Human colon Cells. J. Funct. Foods 4 (1), 185-196.

Guo, Y., Zhou, J., Wen, J., Sun, G., and Sun, Y. (2015). Structural Transformations of Triploid of Populus Tomentosa Carr. Lignin during Auto-Catalyzed Ethanol Organosolv Pretreatment. Ind. Crops Prod. 76, 522-529. doi:10.1016/ j.indcrop.2015.06.020

Harvey, B. G., Guenthner, A. J., Meylemans, H. A., Haines, S. R. L., Lamison, K. R., Groshens, T. J., et al. (2015). Renewable Thermosetting Resins and Thermoplastics from Vanillin. Green. Chem. 17 (2), 1249-1258. doi:10.1039/ c4gc01825g

Hoang, A. T., Ong, H. C., Fattah, I. M. R., Chong, C. T., Cheng, C. K., Sakthivel, R., et al. (2021). Progress on the Lignocellulosic Biomass Pyrolysis for Biofuel
Production toward Environmental Sustainability. Fuel Process. Technol. 223, 106997. doi:10.1016/j.fuproc.2021.106997

Holladay, J. E., White, J. F., Bozell, J. J., and Johnson, D. (2007). Top Value-Added Chemicals from Biomass - Volume II-Results of Screening for Potential Candidates from Biorefinery Lignin. Washington, D.C., USA: US Department of Energy.

Hossain, M. M., and Aldous, L. (2012). Ionic Liquids for Lignin Processing: Dissolution, Isolation, and Conversion. Aust. J. Chem. 65 (11), 1465-1477. doi:10.1071/ch12324

Huang, Y., Duan, Y., Qiu, S., Wang, M., Ju, C., Cao, H., et al. (2018). Lignin-first Biorefinery: a Reusable Catalyst for Lignin Depolymerization and Application of Lignin Oil to Jet Fuel Aromatics and Polyurethane Feedstock. Sustain. Energ. Fuels 2 (3), 637-647. doi:10.1039/c7se00535k

Huang, Y., Duan, Y., Qiu, S., Wang, M., Ju, C., Cao, H., Fang, Y., and Tan, T. (2018). Lignin-first Biorefinery: a Reusable Catalyst for Lignin Depolymerization and Application of Lignin Oil to Jet Fuel Aromatics and Polyurethane Feedstock. Sustain. Energ. Fuels 2 (3), 637-647. doi:10.1039/c7se00535k

Ibrahim, M. N. M., Sriprasanthi, R. B., Shamsudeen, S., Adam, F., and Bhawani, S. A. (2012). A Concise Review of the Natural Existance, Synthesis, Properties, and Applications of Syringaldehyde. BioResources 7 (3), 4377-4399.

Ito, Y., Akao, Y., Shimazawa, M., Seki, N., Nozawa, Y., and Hara, H. (2007). Lig-8, a Highly Bioactive Lignophenol Derivative from Bamboo Lignin, Exhibits Multifaceted Neuroprotective Activity. CNS Drug Rev. 13 (3), 296-307. doi:10.1111/j.1527-3458.2007.00017.x

Ito, Y., Shimazawa, M., Akao, Y., Nakajima, Y., Seki, N., Nozawa, Y., et al. (2006). Lig-8, a Bioactive Lignophenol Derivative from Bamboo Lignin, Protects against Neuronal Damage In Vitro and In Vivo. J. Pharmacol. Sci. 102 (2), 196-204. doi:10.1254/jphs.fp0060711

Kang, S., Li, X., Fan, J., and Chang, J. (2013). Hydrothermal Conversion of Lignin: A Review. Renew. Sustain. Energ. Rev. 27, 546-558. doi:10.1016/ j.rser.2013.07.013

Karthikeyan, S., Kanimozhi, G., Prasad, N. R., and Mahalakshmi, R. (2011). Radiosensitizing Effect of Ferulic Acid on Human Cervical Carcinoma Cells In Vitro. Toxicol. Vitro 25 (7), 1366-1375. doi:10.1016/j.tiv.2011.05.007

Katahira, R., Elder, T. J., and Beckham, G. T. (2018). Chapter 1. A Brief Introduction to Lignin Structure. Lignin Valor. Emerging Approaches 2018, 1-20. doi:10.1039/9781788010351-00001

Kuamr, K. S., Varma, C. P., Reena, V. N., and Aravindakshan, K. K. (2017a). Synthesis, Characterization, Cytotoxic, Anticancer and Antimicrobial Studies of Novel Schiff Base Ligand Derived from Vanillin and its Transition Metal Complexes. J. Pharm. Sci. Res. 9 (8), 1317.

Kumar, G., Shobana, S., Chen, W., Bach, Q., Kim, S., Atabani, A., et al. (2017b). A Review of Thermochemical Conversion of Microalgal Biomass for Biofuels: Chemistry and Processes. Green. Chem. 19 (1). doi:10.1039/c6gc01937d

Kumar, L. V., Sunitha, S., and Nath, G. R. (2021). Antioxidant, Antidiabetic and Anticancer Studies of Nickel Complex of Vanillin-4-Methyl-4-Phenyl-3Thiosemicarbazone. Mat. Today 41. doi:10.1016/j.matpr.2020.05.376

Kumar, N., and Pruthi, V. (2014). Potential Applications of Ferulic Acid from Natural Sources. Biotechnol. Rep. 4 (1), 86-93. doi:10.1016/j.btre.2014.09.002

Lange, H., Decina, S., and Crestini, C. (2013). Oxidative Upgrade of Lignin - Recent Routes Reviewed. Eur. Polym. J. 49 (6), 1151-1173. doi:10.1016/ j.eurpolymj.2013.03.002

Laurichesse, S., and Avérous, L. (2014). Chemical Modification of Lignins: Towards Biobased Polymers. Prog. Polym. Sci. 39 (7), 1266-1290. doi:10.1016/ j.progpolymsci.2013.11.004

Lee, J.-B., Yamagishi, C., Hayashi, K., and Hayashi, T. (2011). Antiviral and Immunostimulating Effects of Lignin-Carbohydrate-Protein Complexes fromPimpinella Anisum. Biosci. Biotechnol. Biochem. 75 (3), 459-465. doi:10.1271/bbb.100645

Li, M., Gu, M.-M., Lang, Y., Shi, J., Chen, B. P. C., Guan, H., et al. (2019). The Vanillin Derivative VND3207 Protects Intestine against Radiation Injury by Modulating P53/NOXA Signaling Pathway and Restoring the Balance of Gut Microbiota. Free Radic. Biol. Med. 145, 223-236. doi:10.1016/ j.freeradbiomed.2019.09.035

Li, R., Ouda, R., Kimura, C., Narita, R., Nishimura, H., Fujita, T., et al. (2021). Conversion of Beech Wood into Antiviral Lignin-Carbohydrate Complexes by Microwave Acidolysis. ACS Sustain. Chem. Eng. 2021 (9), 9248-9256. doi:10.1021/acssuschemeng.1c01450 
Li, T., and Takkellapati, S. (2018). The Current and Emerging Sources of Technical Lignins and Their Applications. Biofuels, Bioprod. Bioref. 12 (5), 756-787. doi:10.1002/bbb.1913

Lievonen, M., Valle-Delgado, J. J., Mattinen, M.-L., Hult, E.-L., Lintinen, K., Kostiainen, M. A., et al. (2016). A Simple Process for Lignin Nanoparticle Preparation. Green. Chem. 18 (5), 1416-1422. doi:10.1039/c5gc01436k

Liu, W.-J., Jiang, H., and Yu, H.-Q. (2015). Thermochemical Conversion of Lignin to Functional Materials: A Review and Future Directions. Green. Chem. 17 (11), 4888-4907. doi:10.1039/c5gc01054c

Llevot, A., Grau, E., Carlotti, S., Grelier, S., and Cramail, H. (2016). From LigninDerived Aromatic Compounds to Novel Biobased Polymers. Macromol. Rapid Commun. 37 (1), 9-28. doi:10.1002/marc.201500474

Lochab, B., Shukla, S., and Varma, I. K. (2014). Naturally Occurring Phenolic Sources: Monomers and Polymers. RSC Adv. 4 (42), 21712-21752. doi:10.1039/ c4ra00181h

Lu, Q., Zhu, M., Zu, Y., Liu, W., Yang, L., Zhang, Y., et al. (2012). Comparative Antioxidant Activity of Nanoscale Lignin Prepared by a Supercritical Antisolvent (SAS) Process with Non-nanoscale Lignin. Food Chem. 135 (1), 63-67. doi:10.1016/j.foodchem.2012.04.070

Ma, W., Li, X., Song, P., Zhang, Q., Wu, Z., Wang, J., et al. (2019). A Vanillin Derivative Suppresses the Growth of HT29 Cells through the Wnt/ $\beta$-Catenin Signaling Pathway. Eur. J. Pharmacol. 849, 43-49. doi:10.1016/ j.ejphar.2019.01.047

Mahmood, N., Yuan, Z., Schmidt, J., and Xu, C. (2013). Production of Polyols via Direct Hydrolysis of Kraft Lignin: Effect of Process Parameters. Bioresour. Technol. 139 (C), 13-20. doi:10.1016/j.biortech.2013.03.199

Mancuso, C., and Santangelo, R. (2014). Ferulic Acid: Pharmacological and Toxicological Aspects. Food Chem. Toxicol. 65, 185-195. doi:10.1016/ j.fct.2013.12.024

Menter, D. G., Schilsky, R. L., and Dubois, R. N. (2010). Cyclooxygenase-2 and Cancer Treatment: Understanding the Risk Should Be Worth the Reward: Fig. 1. Clin. Cancer Res. 16 (5), 1384-1390. doi:10.1158/1078-0432.ccr-090788

Min, D., Xiang, Z., Liu, J., Jameel, H., Chiang, V., Jin, Y., et al. (2015). Improved Protocol for Alkaline Nitrobenzene Oxidation of Woody and Non-woody Biomass. J. Wood Chem. Technol. 35 (1), 52-61. doi:10.1080/ 02773813.2014.902965

Mohammadi Gheisar, M., and Kim, I. H. (2018). Phytobiotics in Poultry and Swine Nutrition - a Review. Ital. J. Anim. Sci. 17 (1), 92-99. doi:10.1080/ 1828051x.2017.1350120

Mota, M. I. F., Rodrigues Pinto, P. C., Loureiro, J. M., and Rodrigues, A. E. (2015). Recovery of Vanillin and Syringaldehyde from Lignin Oxidation: A Review of Separation and Purification Processes. Separat. Purif. Rev. 45 (3), 227-259. doi:10.1080/15422119.2015.1070178

Mukai, Y., Norikura, T., Fujita, S., Mikame, K., Funaoka, M., and Sato, S. (2011). Effect of Lignin-Derived Lignophenols on Vascular Oxidative Stress and Inflammation in Streptozotocin-Induced Diabetic Rats. Mol. Cel Biochem 348 (1), 117-124. doi:10.1007/s11010-010-0645-9

Muley, P. D., Mobley, J. K., Tong, X., Novak, B., Stevens, J., Moldovan, D., et al. (2019). Rapid Microwave-Assisted Biomass Delignification and Lignin Depolymerization in Deep Eutectic Solvents. Energ. Convers. Manage. 196, 1080-1088. doi:10.1016/j.enconman.2019.06.070

Nair, S. S., Sharma, S., Pu, Y., Sun, Q., Pan, S., Zhu, J. Y., et al. (2014). High Shear Homogenization of Lignin to Nanolignin and Thermal Stability of NanoligninPolyvinyl Alcohol Blends. ChemSusChem 7 (12), 3513-3520. doi:10.1002/ cssc. 201402314

Nanbu, T., Matsuta, T., Sakagami, H., Shimada, J., Maki, J., Makino, T., et al. (2011). Anti-UV Activity of Lentinus Edodes Mycelia Extract (LEM). In Vivo 25 (5), 733-740.

Nanbu, T., Shimada, J., Kobayashi, M., Hirano, K., Koh, T., Machino, M., et al. (2013). Anti-UV Activity of Lignin-Carbohydrate Complex and Related Compounds. In Vivo 27 (1), 133-139.

Nandiwale, K. Y., Danby, A. M., Ramanathan, A., Chaudhari, R. V., Motagamwala, A. H., Dumesic, J. A., et al. (2020). Enhanced AcidCatalyzed Lignin Depolymerization in a Continuous Reactor with Stable Activity. ACS Sustain. Chem. Eng. 8 (10), 4096-4106. doi:10.1021/acssuschemeng.9b06556
Oh-Hara, T., Sakagami, H., Kawazoe, Y., Kaiya, T., Komatsu, N., Ohsawa, N., et al. (1990). Antimicrobial spectrum of lignin-related pine cone extracts of Pinus parviflora Sieb. et Zucc. In Vivo 4, 7-12.

Ou, S., and Kwok, K.-C. (2004). Ferulic Acid: Pharmaceutical Functions, Preparation and Applications in Foods. J. Sci. Food Agric. 84, 1261-1269. doi:10.1002/jsfa.1873

Panzella, L., and Napolitano, A. (2017). Natural Phenol Polymers: Recent Advances in Food and Health Applications. Antioxidants 6 (2), 30-45. doi:10.3390/antiox6020030

Parmar, I., Bhullar, K. S., and Rupasinghe, H. P. V. (2015). "Anti-diabetic Effect of Ferulic Acid and Derivatives: An Update," in Ferulic Acid: Antioxidant Properties, Uses and Potential Health Benefits. Editor B. Warren (Hauppauge, NY, USA: Nova Science Publishers, Inc.), 93-116. 978-1-63463-299-7.

Priefert, H., Rabenhorst, J., and Steinbüchel, A. (2001). Biotechnological Production of Vanillin. Appl. Microbiol. Biotechnol. 56 (3), 296-314. doi:10.1007/s002530100687

Rahimi, A., Ulbrich, A., Coon, J. J., and Stahl, S. S. (2014). Formic-Acid-Induced Depolymerization of Oxidized Lignin to Aromatics. Nature 515 (7526), 249-252. doi:10.1038/nature13867

Rajak, R. C., Saha, P., Singhvi, M., Kwak, D., Kim, D., Lee, H., et al. (2021). An EcoFriendly Biomass Pretreatment Strategy Utilizing Reusable Enzyme Mimicking Nanoparticles for Lignin Depolymerization and Biofuel Production. Green. Chem. 23, 5584-5599. doi:10.1039/d1gc01456k

Ramar, M., Manikandan, B., Raman, T., Priyadarsini, A., Palanisamy, S., Velayudam, M., et al. (2012). Protective Effect of Ferulic Acid and Resveratrol against Alloxan-Induced Diabetes in Mice. Eur. J. Pharmacol. 690 (1-3), 226-235. doi:10.1016/j.ejphar.2012.05.019

Renders, T., Van den Bosch, S., Koelewijn, S.-F., Schutyser, W., and Sels, B. F. (2017). Lignin-first Biomass Fractionation: the Advent of Active Stabilisation Strategies. Energy Environ. Sci. 10, 1551-1557. doi:10.1039/c7ee01298e

Roberts, V. M., Stein, V., Reiner, T., Lemonidou, A., Li, X., and Lercher, J. A. (2011). Towards Quantitative Catalytic Lignin Depolymerization. Chem. Eur. J. 17 (21), 5939-5948. doi:10.1002/chem.201002438

Rojas-Graüa, M. A., Raybaudi-Massiliaa, R. M., Soliva-Fortunya, R. C., AvenaBustillosb, R. J., McHughb, T. H,, and Martín-Bellosoa, O. (2007). Apple PureeAlginate Edible Coating as Carrier of Antimicrobial Agents to Prolong ShelfLife of Fresh-Cut Apples. Postharvest Biol. Technol. 45 (2), 254-264.

Rupasinghe, H. P. V., Boulter-Bitzer, J., Ahn, T., and Odumeru, J. A. (2006). Vanillin Inhibits Pathogenic and Spoilage Microorganisms In Vitro and Aerobic Microbial Growth in Fresh-Cut Apples. Food Res. Int. 39, 575-580. doi:10.1016/j.foodres.2005.11.005

Sakagami, H., Kawano, M., Thet, M. M., Hashimoto, K., Satoh, K., Kanamoto, T., et al. (2011). Anti-HIV and Immunomodulation Activities of Cacao Mass Lignin-Carbohydrate Complex. In Vivo 25 (2), 229-236.

Sakagami, H., Sheng, H., Okudaira, N., Yasui, T., Wakabayashi, H., Jia, J., et al. (2016). Prominent Anti-UV Activity and Possible Cosmetic Potential of LigninCarbohydrate Complex. In Vivo 30 (4), 331-339.

Sakagami, H., Kushida, T., Oizumi, T., Nakashima, H., and Makino, T. (2010). Distribution of Lignin-Carbohydrate Complex in Plant Kingdom and its Functionality as Alternative Medicine. Pharmacol. Ther. 128 (1), 91-105. doi:10.1016/j.pharmthera.2010.05.004

Sagues, W. J., Bao, H., Nemenyi, J. L., and Tong, Z. (2018). Lignin-First Approach to Biorefining: Utilizing Fenton's Reagent and Supercritical Ethanol for the Production of Phenolics and Sugars. ACS Sustain. Chem. Eng. 6 (4). doi:10.1039/C7EE01298E

Sato, S., Fujita, S., Funaoka, M., Komori, M., and Kurasaki, M. (2006). Protective Effect of Lignophenol Derivative from Beech (Fagus Crenata Blume) on Copper- and Zinc-Mediated Cell Death in PC12 Cells. Basic Clin. Pharmacol. Toxicol. 99 (5), 353-357. doi:10.1111/j.1742-7843.2006.pto_535.x

Sato, S., Mukai, Y., Tokuoka, Y., Mikame, K., Funaoka, M., and Fujita, S. (2012). Effect of Lignin-Derived Lignophenols on Hepatic Lipid Metabolism in Rats Fed a High-Fat Diet. Environ. Toxicol. Pharmacol. 34 (2), 228-234. doi:10.1016/ j.etap.2012.04.005

Sato, S., Mukai, Y., Yamate, J., Norikura, T., Morinaga, Y., Mikame, K., et al. (2009). Lignin-derived Lignophenols Attenuate Oxidative and Inflammatory Damage to the Kidney in Streptozotocin-Induced Diabetic Rats. Free Radic. Res. 43 (12), 1205-1213. doi:10.3109/10715760903247264 
Sefi, M., Elwej, A., Chaâbane, M., Bejaoui, S., Marrekchi, R., Jamoussi, K., et al. (2019). Beneficial Role of Vanillin, a Polyphenolic Flavoring Agent, on ManebInduced Oxidative Stress, DNA Damage, and Liver Histological Changes in Swiss Albino Mice. Hum. Exp. Toxicol. 38 (6), 619-631. doi:10.1177/ 0960327119831067

Shen, D., Liu, N., Dong, C., Xiao, R., and Gu, S. (2015). Catalytic Solvolysis of Lignin with the Modified HUSYs in Formic Acid Assisted by Microwave Heating. Chem. Eng. J. 270, 641-647. doi:10.1016/j.cej.2015.02.003

Shu, R., Xu, Y., Ma, L., Zhang, Q., Wang, C., and Chen, Y. (2018). Controllable Production of Guaiacols and Phenols from Lignin Depolymerization Using Pd/ C Catalyst Cooperated with Metal Chloride. Chem. Eng. J. 338, 457-464. doi:10.1016/j.cej.2018.01.002

Shu, R., Xu, Y., Ma, L., Zhang, Q., Wang, C., and Chen, Y. (2018). Controllable Production of Guaiacols and Phenols from Lignin Depolymerization Using Pd/ C Catalyst Cooperated with Metal Chloride. Chem. Eng. J. 338, 457-464. doi:10.1016/j.cej.2018.01.002

Singh, R., Prakash, A., Dhiman, S. K., Balagurumurthy, B., Arora, A. K., Puri, S. K., et al. (2014). Hydrothermal Conversion of Lignin to Substituted Phenols and Aromatic Ethers. Bioresour. Technol. 165 (C), 319-322. doi:10.1016/ j.biortech.2014.02.076

Singh, R., Singh, S., Trimukhe, K. D., Pandare, K. V., Bastawade, K. B., Gokhale, D. V., et al. (2005). Lignin-carbohydrate Complexes from Sugarcane Bagasse: Preparation, Purification, and Characterization. Carbohydr. Polym. 62 (1), 57-66. doi:10.1016/j.carbpol.2005.07.011

Song, Y., Wu, T., Yang, Q., Chen, X., Wang, M., Wang, Y., et al. (2014). Ferulic Acid Alleviates the Symptoms of Diabetes in Obese Rats. J. Funct. Foods 9 (C), 141-147. doi:10.1016/j.jff.2014.04.007

Sri Balasubashini, M., Rukkumani, R., and Menon, V. P. (2003). Protective Effects of Ferulic Acid on Hyperlipidemic Diabetic Rats. Acta Diabetol. 40 (3), 118-122. doi:10.1007/s00592-003-0099-6

Stark, A. (2010). Ionic Liquids in the Biorefinery: A Critical Assessment of Their Potential. Energ. Environ. Sci. 4 (1), 19-32.

Strassberger, Z., Prinsen, P., Klis, F. V. D., Es, D. S. V., Tanase, S., and Rothenberg, G. (2015). Lignin Solubilisation and Gentle Fractionation in Liquid Ammonia. Green. Chem. 17 (1), 325-334. doi:10.1039/c4gc01143k

Sun, Z., Fridrich, B., De Santi, A., Elangovan, S., and Barta, K. (2018). Bright Side of Lignin Depolymerization: Toward New Platform Chemicals. Chem. Rev. 118 (2), 614-678. doi:10.1021/acs.chemrev.7b00588

Suzuki, H., Iiyama, K., Yoshida, O., Yamazaki, S., Yamamoto, N., and Toda, S. (1990). Structural Characterization of the Immunoactive and Antiviral WaterSolubilized Lignin in an Extract of the Culture Medium of Lentinus Edodes Mycelia (LEM). Agric. Biol. Chem. 54 (2), 479-487. doi:10.1271/bbb1961.54.479

Tai, A., Sawano, T., Yazama, F., and Ito, H. (2011). Evaluation of Antioxidant Activity of Vanillin by Using Multiple Antioxidant Assays. Biochim. Biophys. Acta (Bba) - Gen. Subjects 1810 (2), 170-177. doi:10.1016/ j.bbagen.2010.11.004

Tarabanko, V. E., and Tarabanko, N. (2017). Catalytic Oxidation of Lignins into the Aromatic Aldehydes: General Process Trends and Development Prospects. Int. J. Mol. Sci. 18 (11). doi:10.3390/ijms18112421

Tayier, M., Duan, D., Zhao, Y., Ruan, R., Wang, Y., and Liu, Y. (2017). Catalytic Effects of Various Acids on Microwave-Assisted Depolymerization of Organosolv Lignin. BioResources 13 (1), 412-424. doi:10.15376/ biores.13.1.412-424

Thoresen, P. P., Matsakas, L., Rova, U., and Christakopoulos, P. (2020). Recent Advances in Organosolv Fractionation: Towards Biomass Fractionation Technology of the Future. Bioresour. Technol. 306, 123189. doi:10.1016/ j.biortech.2020.123189

Toledano, A., Serrano, L., and Labidi, J. (2012). Organosolv Lignin Depolymerization with Different Base Catalysts. J. Chem. Technol. Biotechnol. 87 (11), 1593-1599. doi:10.1002/jctb.3799

Toledano, A., Serrano, L., Pineda, A., Romero, A. A., Luque, R., and Labidi, J. (2014). Microwave-assisted Depolymerisation of Organosolv Lignin via Mild Hydrogen-free Hydrogenolysis: Catalyst Screening. Appl. Catal. B: Environ. 145, 43-55. doi:10.1016/j.apcatb.2012.10.015

Tsuchiya, T., and Takasawa, M. (1975). Oryzanol, Ferulic Acid, and Their Derivatives as Preservatives. Jpn. Kokai 07, 518-521.

Van den Bosch, S., Renders, T., Kennis, S., Koelewijn, S.-F., Van den Bossche, G., Vangeel, T., et al. (2017). Integrating Lignin Valorization and Bio-Ethanol
Production: on the Role of Ni-Al2O3catalyst Pellets during Lignin-First Fractionation. Green. Chem. 19 (14), 3313-3326. doi:10.1039/c7gc01324h

Van Wyk, B., and Wink, M. (2014). Phytomedicines, Herbal Drugs, and Poisons. Chicago: The University of Chicago Press.

Vangeel, T., Schutyser, W., Renders, T., and Sels, B. F. (2018). Perspective on Lignin Oxidation: Advances, Challenges, and Future Directions. Top. Curr. Chem. (Cham) 376 (4), 30-16. doi:10.1007/s41061-018-0207-2

Vinardell, M. P., and Mitjans, M. (2017). Lignins and Their Derivatives with Beneficial Effects on Human Health. Int. J. Mol. Sci. 18 (6). doi:10.3390/ ijms 18061219

Wang, H., Tucker, M., and Ji, Y. (2013). Recent Development in Chemical Depolymerization of Lignin: A Review. J. Appl. Chem. 9, 838645. doi:10.1155/2013/838645

Wang, Y., Dai, L., Fan, L., Shan, S., Liu, Y., and Ruan, R. (2016). Review of Microwave-Assisted Lignin Conversion for Renewable Fuels and Chemicals. J. Anal. Appl. Pyrolysis 119, 104-113. doi:10.1016/j.jaap.2016.01.008

Wang, Y., Wang, D., Li, X., Li, G., Wang, Z., Li, M., et al. (2019). Investigation on the Catalytic Hydrogenolysis of Lignin over NbOx-Ni/ZnO-Al2O3. Ind. Eng. Chem. Res. 58 (19), 7866-7875. doi:10.1021/acs.iecr.9b00376

Weldemhret, T. G., Bañares, A. B., Ramos, K. R. M., Lee, W.-K., Nisola, G. M., Valdehuesa, K. N. G., et al. (2020). Current Advances in Ionic Liquid-Based Pre-treatment and Depolymerization of Macroalgal Biomass. Renew. Energ. 152, 283-299. doi:10.1016/j.renene.2020.01.054

Xiang, Q., and Lee, Y. Y. (2000). Oxidative Cracking of Precipitated Hardwood Lignin by Hydrogen Peroxide. Abab 84-86, 153-162. doi:10.1385/abab:84-86:19:153

Xiao, L.-P., Wang, S., Li, H., Li, Z., Shi, Z.-J., Xiao, L., et al. (2017). Catalytic Hydrogenolysis of Lignins into Phenolic Compounds over Carbon Nanotube Supported Molybdenum Oxide. ACS Catal. 7 (11), 7535-7542. doi:10.1021/ acscatal.7b02563

Xu, C., Arancon, R. A. D., Labidi, J., and Luque, R. (2014). Lignin Depolymerisation Strategies: Towards Valuable Chemicals and Fuels. Chem. Soc. Rev. 43 (22), 7485-7500. doi:10.1039/c4cs00235k

$\mathrm{Xu}, \mathrm{C}$., and Ferdosian, F. (2017). Conversion of Lignin into Bio-Based Chemicals and Materials (Green Chemistry and Sustainable Technology). Berlin: Springer.

Xu, R., Zhang, K., Liu, P., Han, H., Zhao, S., Kakade, A., et al. (2018). Lignin Depolymerization and Utilization by Bacteria. Bioresour. Technol. 269, 557-566. doi:10.1016/j.biortech.2018.08.118

Xu, Y.-H., and Li, M.-F. (2021). Hydrothermal Liquefaction of Lignocellulose for Value-Added Products: Mechanism, Parameter and Production Application. Bioresour. Technol. 342, 126035. doi:10.1016/j.biortech.2021.126035

Xue, L., Yan, L., Cui, Y., Jiang, M., Xu, X., Zhang, S., et al. (2016). Degradation of Lignin in Ionic Liquid with $\mathrm{HCl}$ as Catalyst. Environ. Prog. Sustain. Energ. 35 (3), 809-814. doi:10.1002/ep.12276

Xue, Z., Zhao, X., Sun, R.-c., and Mu, T. (2016). Biomass-Derived $\gamma$-ValerolactoneBased Solvent Systems for Highly Efficient Dissolution of Various Lignins: Dissolution Behavior and Mechanism Study. ACS Sustain. Chem. Eng. 4 (7), 3864-3870. doi:10.1021/acssuschemeng.6b00639

Yang, C., Wang, S., Yang, J., Xu, D., Li, Y., Li, J., et al. (2020). Hydrothermal Liquefaction and Gasification of Biomass and Model Compounds: A Review. Green. Chem. 22, 8210-8232. doi:10.1039/d0gc02802a

Yearla, S., and Padmasree, K. (2015). Preparation and Characterisation of Lignin Nanoparticles: Evaluation of Their Potential as Antioxidants and UV Protectants. J. Exp. Nanoscience 11 (4), 1-14. doi:10.1080/ 17458080.2015 .1055842

You, T.-T., Zhang, L.-M., Zhou, S.-K., and Xu, F. (2015). Structural Elucidation of Lignin-Carbohydrate Complex (LCC) Preparations and Lignin from Arundo donax Linn. Ind. Crops Prod. 71 (C), 65-74. doi:10.1016/j.indcrop.2015.03.070

Yuan, T.-Q., Xu, F., and Sun, R.-C. (2013). Role of Lignin in a Biorefinery: Separation Characterization and Valorization. J. Chem. Technol. Biotechnol. 88 (3), 346-352. doi:10.1002/jctb.3996

Zakzeski, J., Bruijnincx, P. C. A., Jongerius, A. L., and Weckhuysen, B. M. (2010). The Catalytic Valorization of Lignin for the Production of Renewable Chemicals. Chem. Rev. 110 (6), 3552-3599. doi:10.1021/ cr900354u

Zhang, C., Madbouly, S. A., and Kessler, M. R. (2015). Renewable Polymers Prepared from Vanillin and its Derivatives. Macromol. Chem. Phys. 216 (17), 1816-1822. doi:10.1002/macp.201500194 
Zhang, C., and Wang, F. (2020). Catalytic Lignin Depolymerization to Aromatic Chemicals. Acc. Chem. Res. 53 (2), 470-484. doi:10.1021/ acs.accounts.9b00573

Zhang, Y., But, P. P.-H., Ooi, V. E.-C., Xu, H.-X., Delaney, G. D., Lee, S. H. S., et al. (2007). Chemical Properties, Mode of Action, and In Vivo Anti-herpes Activities of a Lignin-Carbohydrate Complex from Prunella Vulgaris. Antiviral Res. 75 (3), 242-249. doi:10.1016/j.antiviral.2007.03.010

Zhao, W., Simmons, B., Singh, S., Ragauskas, A., and Cheng, G. (2016). From Lignin Association to Nano-/micro-Particle Preparation: Extracting Higher Value of Lignin. Green. Chem. 18 (21), 5693-5700. doi:10.1039/ c6gc01813k

Zhao, Y., Shakeel, U., Saif Ur Rehman, M., Li, H., Xu, X., and Xu, J. (2020). Lignin-carbohydrate Complexes (LCCs) and its Role in Biorefinery. J. Clean. Prod. 253, 120076. doi:10.1016/j.jclepro.2020.120076

Zhou, S., Jin, K., and Buehler, M. J. (2021). Understanding Plant Biomass via Computational Modeling. Adv. Mater. 33 (28), 2003206. doi:10.1002/ adma.202003206

Zhu, G., Jin, D., Zhao, L., Ouyang, X., Chen, C., and Qiu, X. (2017). Microwave-assisted Selective Cleavage of C C Bond for Lignin Depolymerization. Fuel Process. Technol. 161, 155-161. doi:10.1016/j.fuproc.2017.03.020
Zhu, X., Peng, C., Chen, H., Chen, Q., Zhao, Z. K., Zheng, Q., et al. (2018). Opportunities of Ionic Liquids for Lignin Utilization from Biorefinery. ChemistrySelect 3 (27), 7945-7962. doi:10.1002/slct.201801393

Conflict of Interest: The authors declare that the research was conducted in the absence of any commercial or financial relationships that could be construed as a potential conflict of interest.

Publisher's Note: All claims expressed in this article are solely those of the authors and do not necessarily represent those of their affiliated organizations, or those of the publisher, the editors and the reviewers. Any product that may be evaluated in this article, or claim that may be made by its manufacturer, is not guaranteed or endorsed by the publisher.

Copyright (C) 2022 Zhou, Thilakarathna, He and Rupasinghe. This is an open-access article distributed under the terms of the Creative Commons Attribution License (CC BY). The use, distribution or reproduction in other forums is permitted, provided the original author(s) and the copyright owner(s) are credited and that the original publication in this journal is cited, in accordance with accepted academic practice. No use, distribution or reproduction is permitted which does not comply with these terms. 